\title{
DISCOVERING UNOBSERVED HETEROGENEITY IN STRUCTURAL EQUATION MODELS TO AVERT VALIDITY THREATS
}

\author{
Jan-Michael Becker \\ Department of Marketing and Brand Management, University of Cologne, \\ Cologne, 50923, GERMANY \{j.becker@wiso.uni-koeln.de\}
}

\begin{abstract}
Arun Rai
Center for Process Innovation and Department of Computer Information Systems, Robinson College of Business, Georgia State University, Atlanta, GA 30303 U.S.A. \{arunrai@gsu.edu\}
\end{abstract}

Christian M. Ringle

Institute for Human Resource Management and Organizations, Hamburg University of Technology (TUHH), Hamburg, 21073, GERMANY \{ringle@tuhh.de\} and

Faculty of Business and Law, University of Newcastle, Callaghan, NSW 2308 AUSTRALIA \{christian.ringle@newcastle.edu.au\}

\section{Franziska Völckner}

Department of Marketing and Brand Management, University of Cologne,

Cologne, 50923, GERMANY \{voelckner@wiso.uni-koeln.de\}

\section{Appendix A}

\section{Meta-Analyses of Information Systems Studies}

\begin{tabular}{|c|c|c|c|c|c|}
\hline IS Phenomenon & $\begin{array}{l}\text { Reference, } \\
\text { Journal }\end{array}$ & Scope & Meta-Analysis Purpose & $\begin{array}{l}\text { Moderators/Contingency } \\
\text { Variables Examined }\end{array}$ & $\begin{array}{l}\text { Nature of Inconsistent Findings } \\
\text { (emphasis added) }\end{array}$ \\
\hline $\begin{array}{l}\text { Decision Support } \\
\text { System (DSS) } \\
\text { Implementation } \\
\text { Success }\end{array}$ & $\begin{array}{l}\text { Alavi and } \\
\text { Joachimsth } \\
\text { aler 1992, } \\
\text { MISQ }\end{array}$ & $\begin{array}{l}144 \\
\text { findings } \\
\text { from } 33 \\
\text { studies }\end{array}$ & $\begin{array}{l}\text { Investigating the relationship } \\
\text { between user-related factors and } \\
\text { DSS implementation success }\end{array}$ & $\begin{array}{l}\text { Authors suggest that } \\
\text { moderators could explain the } \\
\text { large variance in effect sizes } \\
\text { across studies. }\end{array}$ & $\begin{array}{l}\text { "Reviews of information systems } \\
\text { implementation research...have } \\
\text { revealed that collectively, implemen- } \\
\text { tation studies have yielded } \\
\text { conflicting and somewhat } \\
\text { confusing findings." }\end{array}$ \\
\hline $\begin{array}{l}\text { Group Support } \\
\text { Systems (GSS) }\end{array}$ & $\begin{array}{l}\text { Dennis et al. } \\
2001, \text { MISQ }\end{array}$ & 61 articles & $\begin{array}{l}\text { Developing a new model for } \\
\text { interpreting GSS effects on firm } \\
\text { performance. }\end{array}$ & $\begin{array}{l}\text { - Fit between the Task and } \\
\text { the GSS Structures } \\
\text { - Appropriation Support } \\
\text { Received }\end{array}$ & $\begin{array}{l}\text { "Many previous papers have } \\
\text { lamented the fact that the findings of } \\
\text { past GSS research have been } \\
\text { inconsistent. This paper develops } \\
\text { a new model for interpreting GSS } \\
\text { effects on performance..." }\end{array}$ \\
\hline
\end{tabular}




\begin{tabular}{|c|c|c|c|c|c|}
\hline IS Phenomenon & $\begin{array}{l}\text { Reference, } \\
\text { Journal }\end{array}$ & Scope & Meta-Analysis Purpose & $\begin{array}{l}\text { Moderators/Contingency } \\
\text { Variables Examined }\end{array}$ & $\begin{array}{l}\text { Nature of Inconsistent Findings } \\
\text { (emphasis added) }\end{array}$ \\
\hline $\begin{array}{l}\text { IT Investment } \\
\text { Payoff }\end{array}$ & $\begin{array}{l}\text { Kohli and } \\
\text { Deveraj } \\
\text { 2003, ISR }\end{array}$ & 66 studies & $\begin{array}{l}\text { Examining structural variables that } \\
\text { explain why some IT payoff studies } \\
\text { observe a positive effect and some } \\
\text { do not. }\end{array}$ & $\begin{array}{l}\text { - Dependent Classification } \\
\text { - Sample Size } \\
\text { - Data Source } \\
\text { - Type of IT Impact } \\
\text { - Type of IT Assets } \\
\text { - Industry }\end{array}$ & $\begin{array}{l}\text { "...some studies have shown mixed } \\
\text { results in establishing a relationship } \\
\text { between IT investment and firm } \\
\text { performance." }\end{array}$ \\
\hline $\begin{array}{l}\text { IT Innovation } \\
\text { Adoption }\end{array}$ & $\begin{array}{l}\text { Lee and Xia } \\
2006, \text { I\&M }\end{array}$ & $\begin{array}{l}54 \text { correla- } \\
\text { tions from } \\
21 \text { studies }\end{array}$ & $\begin{array}{l}\text { Investigating the effects of } \\
\text { organizational size on IT innovation } \\
\text { adoption. }\end{array}$ & $\begin{array}{l}\text { - Type of Innovation } \\
\text { - Type of Organization } \\
\text { - Stage of Adoption } \\
\text { - Scope of Size } \\
\text { - Industry Sector }\end{array}$ & $\begin{array}{l}\text { "...empirical results on the } \\
\text { relationship between them have } \\
\text { been disturbingly mixed and } \\
\text { inconsistent...explain and resolve } \\
\text { these mixed results by... examining } \\
\text { the effects of six moderators on the } \\
\text { relationship." }\end{array}$ \\
\hline $\begin{array}{l}\text { IT Project } \\
\text { Escalation }\end{array}$ & $\begin{array}{l}\text { Wang and } \\
\text { Keil 2007, } \\
\text { IRMJ }\end{array}$ & $\begin{array}{l}12 \text { articles } \\
\text { with } \\
20 \text { separate } \\
\text { experiment } \\
\mathrm{s}\end{array}$ & $\begin{array}{l}\text { Investigating the effect size of sunk } \\
\text { cost on project escalation and deter- } \\
\text { mining whether there is a difference } \\
\text { in effect sizes between IT and non- } \\
\text { IT projects. }\end{array}$ & - IT vs. Non-IT Projects & $\begin{array}{l}\text { "...because of the strong magnitude } \\
\text { and heterogeneity of effect sizes } \\
\text { for the sunk cost effect, we need } \\
\text { more primary studies that } \\
\text { investigate potential moderators of } \\
\text { sunk cost." }\end{array}$ \\
\hline $\begin{array}{l}\text { Turnover of IT } \\
\text { Professionals }\end{array}$ & $\begin{array}{l}\text { Joseph et } \\
\text { al. } 2007 \\
\text { MISQ }\end{array}$ & 33 studies & $\begin{array}{l}\text { Integrating the } 43 \text { antecedents of } \\
\text { turnover intentions of IT } \\
\text { professionals in a unified framework } \\
\text { using meta-analytic structural } \\
\text { equation modeling. }\end{array}$ & $\begin{array}{l}\text { - Age } \\
\text { - Gender Ratio of Sample } \\
\text { - Operationalization of } \\
\text { Turnover Intention } \\
\text { - Operationalization of } \\
\text { Antecedents }\end{array}$ & $\begin{array}{l}\text { "...our narrative review finds several } \\
\text { inconsistent (e.g., organization } \\
\text { tenure and role conflict) and } \\
\text { inconclusive (e.g., age and gender) } \\
\text { findings." }\end{array}$ \\
\hline \multirow{3}{*}{$\begin{array}{l}\text { IS } \\
\text { Implementation } \\
\text { Success }\end{array}$} & $\begin{array}{l}\text { Sharma and } \\
\text { Yetton } \\
\text { 2003, MISQ }\end{array}$ & 22 studies & $\begin{array}{l}\text { Proposing a contingent model in } \\
\text { which task interdependence } \\
\text { moderates the effect of } \\
\text { management support on } \\
\text { implementation success. }\end{array}$ & - Task Interdependence & $\begin{array}{l}\text { "A meta-analysis of the empirical } \\
\text { literature provides strong support for } \\
\text { the model and begins to explain the } \\
\text { wide variance in empirical } \\
\text { findings." } \\
\text { "The theory developed and findings } \\
\text { reported above help to explain the } \\
\text { inconsistent findings in the } \\
\text { literature." }\end{array}$ \\
\hline & $\begin{array}{l}\text { Sabherwal } \\
\text { et al. 2006, } \\
\text { Mgmt.Scien } \\
\text { ce }\end{array}$ & $\begin{array}{l}612 \\
\text { findings } \\
\text { from } 121 \\
\text { studies }\end{array}$ & $\begin{array}{l}\text { Explaining the interrelationships } \\
\text { among four constructs representing } \\
\text { the success of a specific information } \\
\text { system and the relationships of } \\
\text { these IS success constructs with } \\
\text { four user-related constructs and two } \\
\text { constructs representing the context. }\end{array}$ & $\begin{array}{l}\text { Authors suggest that possible } \\
\text { moderators include voluntari- } \\
\text { ness of IS adoption and user } \\
\text { characteristics such as age } \\
\text { and gender. }\end{array}$ & $\begin{array}{l}\text { "Despite considerable empirical } \\
\text { research, results on the } \\
\text { relationships among constructs } \\
\text { related to information system (IS) } \\
\text { success, as well as the determinants } \\
\text { of IS success, are often } \\
\text { inconsistent." }\end{array}$ \\
\hline & $\begin{array}{l}\text { Sharma and } \\
\text { Yetton } \\
\text { 2007, MISQ }\end{array}$ & 27 studies & $\begin{array}{l}\text { Proposing a contingent model in } \\
\text { which the effect of training on IS } \\
\text { implementation success is a } \\
\text { function of technical complexity and } \\
\text { task interdependence. }\end{array}$ & $\begin{array}{l}\text { - Technical Complexity } \\
\text { - Task Interdependence }\end{array}$ & $\begin{array}{l}\text { "Research has investigated the main } \\
\text { effect of training on information } \\
\text { systems implementation success. } \\
\text { However, empirical support for } \\
\text { this model is inconsistent." }\end{array}$ \\
\hline
\end{tabular}




\begin{tabular}{|c|c|c|c|c|c|}
\hline IS Phenomenon & $\begin{array}{l}\text { Reference, } \\
\text { Journal }\end{array}$ & Scope & Meta-Analysis Purpose & $\begin{array}{l}\text { Moderators/Contingency } \\
\text { Variables Examined }\end{array}$ & $\begin{array}{l}\text { Nature of Inconsistent Findings } \\
\text { (emphasis added) }\end{array}$ \\
\hline \multirow{3}{*}{$\begin{array}{l}\text { Technology } \\
\text { Acceptance }\end{array}$} & $\begin{array}{l}\text { King and } \mathrm{He} \\
2006,1 \& \mathrm{M}\end{array}$ & 88 studies & $\begin{array}{l}\text { Summarizing TAM research and } \\
\text { investigating conditions under which } \\
\text { TAM may have different effects. }\end{array}$ & $\begin{array}{l}\text { - Type of Users } \\
\text { - Type of Usage }\end{array}$ & $\begin{array}{l}\text { "...all TAM relationships are not } \\
\text { borne out in all studies; there is } \\
\text { wide variation in the predicted } \\
\text { effects in various studies..." } \\
\text { "Since there are inconsistencies in } \\
\text { TAM results, a meta-analysis is } \\
\text { more likely to appropriately integrate } \\
\text { the positive and the negative." }\end{array}$ \\
\hline & $\begin{array}{l}\text { Schepers } \\
\text { and Wetzels } \\
\text { 2007, I\&M }\end{array}$ & $\begin{array}{l}51 \text { articles } \\
\text { containing } \\
63 \text { studies }\end{array}$ & $\begin{array}{l}\text { Analyzing the role of subjective } \\
\text { norms and three inter-study } \\
\text { moderating factors. }\end{array}$ & $\begin{array}{l}\text { - Type of Respondents } \\
\text { - Type of Technology } \\
\text { - Culture }\end{array}$ & $\begin{array}{l}\text { "First, the subjective norm has had a } \\
\text { mixed and inconclusive } \\
\text { role.... Some studies found } \\
\text { considerable impacts of it on the } \\
\text { dependent variables. However, } \\
\text { others did not find significant } \\
\text { effects." }\end{array}$ \\
\hline & $\begin{array}{l}\text { Wu and } \\
\text { Lederer } \\
2009 \\
\text { MISQ }\end{array}$ & 71 studies & $\begin{array}{l}\text { Investigating the impact of } \\
\text { environment-based voluntariness on } \\
\text { the relationships among the four } \\
\text { primary TAM constructs (i.e., ease } \\
\text { of use, perceived usefulness, } \\
\text { behavioral intention, and usage). }\end{array}$ & $\begin{array}{l}\text { - Environment-Based } \\
\text { Voluntariness }\end{array}$ & $\begin{array}{l}\text { "The } Q \text { statistic for each of the five } \\
\text { correlations exceeded its cutoff, and } \\
\text { thus the analyses confirmed } \\
\text { heterogeneity for each }(p<0.01) \text {. } \\
\text { That is, of all the correlations vary } \\
\text { across studies more than would } \\
\text { be produced by sampling error." }\end{array}$ \\
\hline
\end{tabular}

\section{Appendix B}

\section{Prediction-Oriented Segmentation for PLS Path Modeling (PLS-POS)}

\section{Overview}

As a distance-based segmentation method, the PLS prediction-oriented segmentation (PLS-POS) method builds on earlier work on distancemeasure-based segmentation - that is, the PLS typological path modeling (PLS-TPM) approach (Squillacciotti 2005) and its enhancement, the response-based detection of respondent segments in PLS (REBUS-PLS) (Esposito Vinzi et al. 2008). To extend the distance-measure-based PLS segmentation methods (including overcoming the methodological limitation of PLS-TPM and REBUS-PLS being applicable only to PLS path models with reflective measures (Esposito Vinzi et al. 2008; Sarstedt 2008)), the PLS-POS algorithm introduces three novel features: (1) it uses an explicit PLS-specific objective criterion to form homogeneous groups, (2) it includes a new distance measure that is appropriate for PLS path model with both reflective and formative measures and is able to uncover unobserved heterogeneity in formative measures, and (3) it ensures continuous improvement of the objective criterion throughout the iterations of the algorithm (hill-climbing approach). Table B1 shows the key technical differences of the new PLS-POS method in comparison with the main distance-based methods (i.e., PLS-TPM and REBUSPLS) and the popular finite-mixture method for PLS (i.e., FIMIX-PLS).

The following sections explain in greater detail PLS-POS' distinctive features. To begin with, we focus on the description of PLS-POS' objective criterion. An explanation of the distance measure employed and its extension to use it for formative measurement models follows. Finally, we provide details on the algorithm with its specific steps and procedures and how it ensures the continuous improvement of the objective criterion.

\section{Objective Criterion of PLS-POS}

The main segmentation objective in PLS is to form homogenous groups of observations that show increased endogenous variables' explained variance $\left(R^{2}\right)$ and, thus, provide an improved prediction (compared to the overall sample), which is in accordance with Anderberg's (1973, p. 
Table B1. Comparison of the Technical Differences of FIMIX-PLS, PLS-TPM, REBUS-PLS, and PLS-POS

\begin{tabular}{|c|c|c|c|c|}
\hline & $\begin{array}{l}\text { Finite-Mixture } \\
\text { Segmentation } \\
\text { Approach }\end{array}$ & \multicolumn{3}{|c|}{ Distance-Based Clustering Approaches } \\
\hline Algorithm Feature & $\begin{array}{l}\text { FIMIX-PLS } \\
\text { (Hahn et al. 2002) }\end{array}$ & $\begin{array}{l}\text { PLS-TPM } \\
\text { (Squillacciotti 2005; } \\
\text { Squillacciotti 2010) }\end{array}$ & $\begin{array}{l}\text { REBUS-PLS } \\
\text { (Esposito Vinzi et al. 2010; } \\
\text { Esposito Vinzi et al. 2008) }\end{array}$ & PLS-POS \\
\hline $\begin{array}{l}\text { Distributional } \\
\text { Assumptions }\end{array}$ & Yes & No & No & No \\
\hline Pre-clustering & $\begin{array}{l}\text { No pre-clustering; } \\
\text { random split of } \\
\text { observations }\end{array}$ & $\begin{array}{l}\text { Hierarchical } \\
\text { classification based } \\
\text { on redundancy } \\
\text { residuals of the } \\
\text { overall model }\end{array}$ & $\begin{array}{l}\text { Hierarchical classification } \\
\text { based on communality and } \\
\text { structural residuals of the } \\
\text { overall model }\end{array}$ & $\begin{array}{l}\text { No pre-clustering; random } \\
\text { split of observations and } \\
\text { assignment to closest } \\
\text { segment according to the } \\
\text { distance measure }\end{array}$ \\
\hline Distance measure & $\begin{array}{l}\text { Has no distance } \\
\text { measure }^{\dagger}\end{array}$ & $\begin{array}{l}\text { Based on redundancy } \\
\text { residuals of a single } \\
\text { reflective endogenous } \\
\text { latent variable }\end{array}$ & $\begin{array}{l}\text { Based on communality } \\
\text { residuals of all latent vari- } \\
\text { ables and structural } \\
\text { residuals of all endog- } \\
\text { enous latent variables }\end{array}$ & $\begin{array}{l}\text { Based on structural resi- } \\
\text { duals of all endogenous } \\
\text { latent variables with an } \\
\text { extension that also accounts } \\
\text { for heterogeneity in } \\
\text { formative measures }\end{array}$ \\
\hline $\begin{array}{l}\text { Accounts for sources of } \\
\text { heterogeneity in reflec- } \\
\text { tive measures? }\end{array}$ & No & No & Yes & No \\
\hline $\begin{array}{l}\text { Accounts for sources of } \\
\text { heterogeneity in forma- } \\
\text { tive measures? }\end{array}$ & No & $\mathrm{No}^{\ddagger}$ & $\mathrm{No}^{\ddagger}$ & Yes \\
\hline $\begin{array}{l}\text { Accounts for sources of } \\
\text { heterogeneity in the } \\
\text { structural model? }\end{array}$ & Yes & Yes & Yes & Yes \\
\hline $\begin{array}{l}\text { Assignment of } \\
\text { observations to } \\
\text { segments in each } \\
\text { iteration }\end{array}$ & $\begin{array}{l}\text { Proportional assignment } \\
\text { of all observations to all } \\
\text { segments based on the } \\
\text { conditional multivariate } \\
\text { normal densities to } \\
\text { optimize the likelihood } \\
\text { function }\end{array}$ & $\begin{array}{l}\text { Assigns all } \\
\text { observations to the } \\
\text { closest segment }\end{array}$ & $\begin{array}{l}\text { Assigns all observations to } \\
\text { the closest segment }\end{array}$ & $\begin{array}{l}\text { Assigns only one } \\
\text { observation to the closest } \\
\text { segment and assures } \\
\text { improvement of an objective } \\
\text { criterion ( } R^{2} \text { of all } \\
\text { endogenous latent } \\
\text { variables) before accepting } \\
\text { the change }\end{array}$ \\
\hline Stop criterion & $\begin{array}{l}\text { Extremely small } \\
\text { improvement in log } \\
\text { likelihood below critical } \\
\text { value (or maximum } \\
\text { number of iterations) }\end{array}$ & $\begin{array}{l}\text { Stability of the } \\
\text { classes' composition } \\
\text { (no reassignment of } \\
\text { observations); or } \\
\text { maximum number of } \\
\text { iterations }\end{array}$ & $\begin{array}{l}\text { Stability of the classes' } \\
\text { composition (number of re- } \\
\text { assignments below a } \\
\text { critical percentage value of } \\
\text { observations); or maximum } \\
\text { number of iterations }\end{array}$ & $\begin{array}{l}\text { Infinitesimal improvement in } \\
\text { objective criterion (or } \\
\text { maximum number of } \\
\text { iterations) }\end{array}$ \\
\hline
\end{tabular}

${ }^{\dagger}$ FIMIX-PLS assumes that each endogenous latent variable is distributed as a finite mixture of conditional multivariate normal densities. It uses these densities to estimate probabilities of segment memberships for each observation (proportional assignment) to optimize the likelihood function (which implicitly maximizes the segment-specific explained variance as part of the likelihood function).

‡"As in PLS-TPM, ... [REBUS-PLS] 'distance' has, so far, only been implemented on models with reflective blocks. Although this is not to be considered a strict limitation for many applications, it must be pointed out that REBUS-PLS requires all blocks to be reflective" (Esposito Vinzi et al. 2008, p. 444). This requirement for models with only reflective measures also holds for the REBUS-PLS implementation in the PLSPM package (Sánchez and Trinchera 2013) for the statistical software R (R Core Team 2013). 
195) notion of "clustering for maximum prediction." Consequently, possible PLS-specific and, thus, prediction-oriented objective criteria include the following: (1) the sum of the manifest variables' redundancy residuals in the reflective measures, (2) the sum of endogenous latent variables' $R^{2}$ values in the structural model, and (3) the goodness-of-fit criterion (GoF; Tenenhaus et al. 2005) ${ }^{1}$ for assessing both the structural model and the reflective measures.

Including the residual terms of the manifest variables would only be appropriate to assess the explained variance and, thus, the predictive performance in reflective measures. Because PLS path modeling allows for the use of reflective and formative measures, objective criteria that draw on the manifest variables' residual terms do not support the general applicability of PLS-POS in both measurement models (i.e., reflective and formative). Consequently, the redundancy and community residual in the reflective measures, which are also included in the PLS-GoF measure, are not a useful criterion for the purpose of the PLS segmentation method.

An appropriate PLS-specific objective criterion maximizes the sum of the endogenous latent variables' $R^{2}$ values. In accordance with the PLS algorithm's objective (Lohmöller 1989; Wold 1982), PLS-POS focuses on maximizing the predictivity of each group by minimizing the sum of the endogenous latent variables' squared residuals in the PLS path model. Thus, the sum of each group's sum of $R^{2}$ values represents the objective criterion, which is explicitly defined and calculated in the PLS-POS algorithm. Every reassignment of observations in PLS-POS ensures improvement of the objective criterion (hill climbing approach; see description of the algorithm below). This objective criterion is suitable for any PLS path model regardless of whether such models include reflective or formative measures.

\section{Distance Measure}

To reassign observations, PLS-POS builds on the idea of Squillacciotti (2005) and Esposito Vinzi et al. (2008) to use a distance measure. We propose a new distance measure that is applicable to both reflective and formative measures and accounts for heterogeneity in the structural and the formative measurement model. This observation-to-group distance measure identifies appropriate observations to form homogenous groups and thereby depicts suitable candidates to improve the objective criterion. Within a group, each observation's capability to predict the endogenous latent variables in the PLS path model determines its distance to that group: the shorter the distance of observation $i$ to group $g$, the higher the predictivity of observation $i$ in group $g$.

It is important to understand the conceptual difference between observation $i$ 's membership in its current group $k(k=g ; k, g \varepsilon G)$ and its distance to an alternative group $g(k \neq g ; k, g \varepsilon G)$. For every endogenous latent variable $b(b \varepsilon B)$, the latent variable scores of its direct predecessors $Y_{a_{b} i k}^{\text {exogenous }}$ and the corresponding structural model path coefficients $p_{a_{b} g}$ allow for the group-specific prediction of the endogenous latent variable scores $\left(\hat{Y}_{b i g}\right)$ via linear combinations $\left(\hat{Y}_{b i g}=\sum_{a_{b}=1}^{A_{b}} Y_{a_{b} i k}^{\text {exogenous }} \times p_{a_{b} g}\right)$. To calculate $\hat{Y}_{b i g}$, we use the latent variable scores of an observation's current group $k$ and draw on the alternative group $g$ 's PLS path coefficients $p_{a_{b} g}$. The difference between the predicted value $\hat{Y}_{b i g}$ and the current group's latent variable scores $Y_{b i k}$ from the PLS path model estimation is the residual of observation $i$ in group $g$ for the endogenous latent variable $b$ (Equation 1):

$$
e_{b i g}^{2}=\left(\hat{Y}_{b i g}-Y_{b i k}\right)^{2}=\left(\sum_{a_{b}=1}^{A_{b}} Y_{a_{b} o k}^{\text {exogenous }} \times p_{a_{b} g}-Y_{b i k}^{\text {endogenous }}\right)^{2}
$$

The result of $e_{b i g}^{2}$ is an observation's predictivity in its current group when $k=g(k, g \varepsilon G)$. Furthermore, using the path coefficients $p_{a_{b} g}$ of alternative group-specific PLS estimations for $k \neq g(k, g \varepsilon G)$ provides a heuristic outcome for observation $i$ 's predictivity in each of the $G-1$ other possible group assignments. This establishes the new prediction-oriented PLS-POS distance measure, as presented by Equation (2):

$$
D_{k i g}=\sum_{b=1}^{B} \sqrt{\frac{e_{b i g}^{2}}{\sum_{i=1}^{I_{k}} e_{b i g}^{2}}}
$$

The residuals of each observation $i$ are divided by the sum of the residuals of all observations in $i$ 's current group $k\left(I_{k}\right.$; sample size in group $k$ ). This ratio's square root is the distance of an observation $i$ to group $g$ for an endogenous latent variable $b(b \varepsilon B)$. The sum over all

\footnotetext{
${ }^{1}$ Against its naming, PLS-GoF does not represent a measure of fit for PLS path modeling; see Henseler and Sarstedt (2012) for a discussion.
} 
endogenous variables $B$ in the PLS path model provides the total distance measure $D_{k i g}$. The smaller the sum of the endogenous latent variables' squared residual values, the higher the predictivity of observation $i$ in group $g$ of the underlying PLS path model.

The distinction between formative and reflective measures requires that one pays particular attention in PLS path modeling (e.g., Diamantopoulos et al. 2001; Gudergan et al. 2008; Jarvis et al. 2003). Formative measures require (1) taking into account the indicators' heterogeneity for each measurement model within each group and/or (2) uncovering the significant differences in weights between the groups. Therefore, calculating the group-specific residual term in models with formative measures requires an extension of the group-specific residual $e_{b i g}^{2}$ in the distance measure. The latent variable scores $Y_{a_{b} j i k}$ are replaced by linear combinations of the manifest variable scores $x_{a_{b} j i k}$ and the corresponding measurement model's formative weights $\pi_{a_{b} j g}$. Equation (3) shows the calculation of the residual term for formative measures in the PLS path model.

$$
e_{b i g}^{2}=\left(\sum_{a_{b}=1}^{A_{b}} \sum_{j}^{J} x_{a_{b} j i k} \times \pi_{a_{b} j g} \times p_{a_{b} g}-Y_{b i k}^{\text {endogenous }}\right)^{2}
$$

The formative latent variable scores become a group-wise reestimated prediction of the associated manifest variables $j$ when the squared residual is determined.

\section{Algorithm}

The segmentation process starts by randomly partitioning the overall sample into the prespecified number of $G$ equal groups (Figure B1, Step 1). Calculating all group-specific PLS path model estimates reveals each observation's distance to its own and all other $G-1$ groups. A partitioning approach that assigns each observation to the group to which it has the shortest distance improves the initial segmentation.

Subsequently, the PLS-POS algorithm computes the group-specific PLS path modeling results (Figure B1, Step 2), updates the objective function (Figure B1, Step 3), and computes the observations' distances to all groups (Figure B1, Step 4.1). PLS-POS uses the distance measure to reassign observations based on the maximum value of the difference between an observation's distance to its current group (i.e., the group to which the observation has been assigned) and its distance to an alternative group (Equation 4).

$$
\text { difference } \Delta_{k i g}=\text { distance to current group } k\left(D_{k i k}\right) \text { - distance to alternative group } g\left(D_{k i g}\right)
$$

Positive differences indicate that an observation has a shorter distance to the alternative group and, thus, potentially fits better in that group in terms of predictivity. This computation is conducted for all observations (Figure B1, Step 4.1). Each observation's maximum positive difference becomes part of the list of candidates (Figure B1, Step 4.2). Negative values are not considered because reassigning these observations possibly decreases the objective criterion. Subsequently, the candidates are sorted in descending order in terms of their positive distance differences (Figure B1, Step 4.3).

After the STOP statement, PLS-POS provides the group-specific PLS path model estimates for the final segmentation solution (Figure B1, Step 7). The maximum number of iterations should be sufficiently high (e.g., twice the number of observations in the overall sample) to obtain a solution that is close to the global optimum. The maximum search depth equals the number of observations in the sorted list of candidate observations for reassignment and, thus, may not exceed the number of observations in the overall sample. In early explorative research stages, one may use a reduced search depth for performance reasons. However, to determine the final segmentation result, the search depth should equal the maximum number of observations to ensure that the segmentation solution that minimizes the PLS-POS objective criterion (i.e., the endogenous latent variables' $R^{2}$ values in the PLS path model) has been identified.

Finally, three important issues are worth noting. First, PLS-POS only reassigns observations that improve the objective criterion. As such, the algorithm ensures the continuous improvement of the objective criterion and potentially provides a solution that is at least close to the global optimum. Second, in each iteration step, the algorithm changes the assignment of only one observation and calculates the group-specific PLS estimates of all observations and their new distance measures. Thus, in contrast to the alternative distance-based PLS segmentation approaches suggested in the literature to date (e.g., Esposito Vinzi et al. 2008; Squillacciotti 2005), PLS-POS avoids moving a sizeable set (more or less) of similar candidates from one group to another without improving the objective criterion. Third, owing to the implementation of a hillclimbing approach, PLS-POS could face the problem of ending in local optima. Wedel and Kamakura (2000) recommend running hill-climbing algorithms several times to attain alternative starting partitions and, finally, to select the best segmentation solution. The same procedure should be applied in the application of PLS-POS. 
Step 1: Create an initial segmentation to start the algorithm

Step 1.1: Randomly split the overall sample into K equally sized groups

Step 1.2: Compute the group-specific PLS estimates for the path model

Step 1.3: Establish each observation's distance to each group

Step 1.4: Assign each observation to the closest group

DO LOOP

Step 2: Compute the group-specific PLS estimates for the path model

Step 3: Determine the result of the objective criterion

Step 4: Create a list of candidate observations for reassignment

Step 4.1: Establish the K-1 differences between each observation's distance to its current group and an alternative group

Step 4.2: IF an observation has one or more positive differences of distances, then

Add the maximum difference and the observation's corresponding alternative group assignment to a list of candidates

ELSE: Do nothing

Step 4.3: IF the list is empty, then

GO TO STOP

ELSE: Sort the list of candidate observations in descending order in terms of their positive distance differences

Step 5: Improve the segmentation result

Step 5.1: Select the first observation in the list of candidate observations for reassignment

DO LOOP

Step 5.2: Reassign the observation

Step 5.2: Compute the group-specific PLS estimates for the path model

Step 5.3: Determine the result of the objective criterion

Step 5.4: IF the observation's reassignment improves the objective criterion, then

Save the current assignment and GO TO Step 6

ELSE: Undo changes and continue with Step 5.5

Step 5.5: IF the list contains a subsequent observation following the currently selected observation on the list of candidates AND the maximum search depth has not been reached, then

Select the next observation

ELSE: GO TO Step 6

UNTIL the objective criterion is improved

Step 6: IF the maximum number of iterations OR the maximum search depth has been reached, then

GO TO STOP

ELSE: GO TO Step 2

UNTIL STOP

Step 7: Compute the group-specific PLS path model estimates and provide the final segmentation results

\section{Figure B1. The PLS-POS Algorithm}

\section{Appendix C}

\section{Design of the Multicollinearity Factor for the Simulation Study}

The design of the simulation study for the formative measurement model includes three levels of multicollinearity between the formative indicators in the model. To simulate different levels of multicollinearity, we revert to Mason and Perreault's (1991) seminal study on multicollinearity (see also Grewal et al. 2004). We vary two levels of correlation patterns among the predictor variables reflecting conditions typically encountered by researchers and practitioners. In addition, a situation in which the indicators are uncorrelated (orthogonal) serves as a baseline for comparison (i.e., a perfect formative measure) because this model is unaffected by multicollinearity. 
Table $\mathrm{C} 1$ shows the two multicollinearity levels based on Mason and Perreault, including the trace of $\left(\mathrm{X}^{\prime} \mathrm{X}\right)^{-1}, \operatorname{det}\left(\mathrm{X}^{\prime} \mathrm{X}\right)$, and condition number, as well as each variable's variance inflation factor (VIF) associated with a given level of multicollinearity.

\begin{tabular}{|c|c|c|c|c|c|c|c|c|c|}
\hline & & \multicolumn{4}{|c|}{ Level 1} & \multicolumn{4}{|c|}{ Level 2} \\
\hline & & $\mathrm{X}_{1}$ & $X_{2}$ & $\mathbf{X}_{3}$ & $X_{4}$ & $\mathrm{X}_{1}$ & $X_{2}$ & $X_{3}$ & $X_{4}$ \\
\hline & $X_{1}$ & 1.00 & & & & 1.00 & & & \\
\hline & $\mathrm{X}_{2}$ & .65 & 1.00 & & & .80 & 1.00 & & \\
\hline & $\mathrm{X}_{3}$ & .40 & .40 & 1.00 & & .60 & .60 & 1.00 & \\
\hline & $\mathrm{X}_{4}$ & .00 & .00 & .00 & 1.00 & .00 & .00 & .00 & 1.00 \\
\hline VIF & & 1.80 & 1.80 & 1.24 & 1.00 & 2.96 & 2.96 & 1.67 & 1.00 \\
\hline Trace $\left(X^{\prime} X\right)^{-1}$ & & & & & 5.85 & & & & 8.59 \\
\hline $\operatorname{Det}\left(X^{\prime} X\right)$ & & & & & .47 & & & & .22 \\
\hline Condition no. & & & & & 2.38 & & & & 3.42 \\
\hline
\end{tabular}

Note: VIF = variance inflation factor

\section{Appendix D}

\section{Simulation on the Effects of Unobserved Heterogeneity}

The objective of this simulation study is to evaluate the implications of unobserved heterogeneity for structural model parameter estimates in PLS path models. The results show that unobserved heterogeneity has a strong adverse effect on PLS estimation outcomes: (1) parameter estimates are biased, (2) nonsignificant path coefficients at the group level become significant at the overall sample level that combines groups, (3) sign differences in the parameter estimates between groups are manifested as nonsignificant results at the overall sample level, and (4) explained variance of the model ( $R^{2}$ of the endogenous variables) decreases. These erroneous estimates can lead to both Type I and Type II errors and to invalid inferences.

The simulation study uses a path model with two exogenous variables having a direct effect on one endogenous variable (all variables measured with five reflective indicators). We generate data for the true path coefficients of two groups by considering three situations of unobserved heterogeneity:

- Situation 1, where the path coefficients between group 1 and group 2 differ but show the same sign. We consider scenarios where all parameter estimates are positive (situation 1a) and negative (situation 1b) and where the magnitude in parameter differences between groups is low (.1) and high (.5).

- Situation 2, where unobserved heterogeneity causes sign reversal in parameter estimates across the two groups (i.e., group 1 has a positive path coefficient, while group 2 has a negative one).

- Situation 3, where one group has a nonsignificant parameter estimate and the other group has a significant parameter estimate. We distinguish between two different levels of parameter differences represented by the effect size of the significant parameter, namely .2 and .7.

We generated 100 sets of data for each condition and estimated the group-specific path coefficients, the overall sample path coefficients, and the t-values of these coefficients by employing the bootstrapping procedure on 1,000 subsamples (Henseler et al. 2009).

Table D1 presents the results. The left side shows the group-specific mean estimates of the path coefficients and their average t-values. ${ }^{2}$ The columns on the right side show the mean path coefficients of the overall sample and the interpretation of the results in terms of bias, Type I and II errors, and variance explained $\left(R^{2}\right)$.

\footnotetext{
${ }^{2}$ For a significance level of $\alpha=0.05$ the $\mathrm{t}$-value has to exceed the threshold of 1.98 in these conditions.
} 
The results show that in all situations, biases in the parameter estimates distort effect sizes and cause misinterpretation of the path coefficients, which is especially problematic for comparative hypotheses (e.g., path coefficient $1>$ path coefficient 2 ). Type I and Type II errors are exacerbated in situations where the group-specific parameters show inconsistent signs (i.e., situation 2 where signs are reversed across groups) and when at least one of the groups involves nonsignificant parameters while the other group does not (i.e., situation 3). In contrast, when all parameters are significant and show the same sign (situation 1), our results suggest that it is not very likely that Type II errors occur. In this situation, the existence of Type II errors depends on the effect size and the degree to which the increased power of the combined sample size compensates for the increase in standard errors due to unobserved heterogeneity. For all parameter constellations in our simulation study, the increased sample size compensates for the increase in standard errors.

The $R^{2}$ decreases in almost all situations, implying an inferior model fit at the overall sample level. We find particularly strong decreases in $R^{2}$ in situations in which the group-specific effect sizes are high; in contrast, $R^{2}$ is almost unaffected in situations showing low group-specific effect sizes.

\section{Table D1. Results of the Simulation Study}

\begin{tabular}{|c|c|c|c|c|c|c|c|}
\hline \multicolumn{3}{|c|}{$\begin{array}{c}\text { Group-Specific } \\
\text { Parameter Estimates }\end{array}$} & \multicolumn{5}{|c|}{ Pooled Parameter Estimate } \\
\hline & $\begin{array}{l}\text { Group } 1 \\
(n=200)\end{array}$ & $\begin{array}{c}\text { Group 2 } \\
(n=200)\end{array}$ & $\begin{array}{l}\text { Parameter } \\
(\mathrm{n}=400)\end{array}$ & Biased? & $\begin{array}{l}\text { Type I } \\
\text { Error }\end{array}$ & $\begin{array}{l}\text { Type II } \\
\text { Error }\end{array}$ & Lower $R^{2}$ \\
\hline \multirow{2}{*}{$1 a}$. & $\begin{array}{c}.7(t=18.57) \\
.2(t=3.94) \\
R^{2}=.53\end{array}$ & $\begin{array}{c}.2(t=3.84) \\
.7(t=19.64) \\
R^{2}=.53\end{array}$ & $\begin{aligned} .45(t=11.36) \\
.45(t=11.54) \\
R^{2}=.41\end{aligned}$ & Yes & - & No & Yes \\
\hline & $\begin{array}{c}.3(t=4.95) \\
.2(t=3.31) \\
R^{2}=.13\end{array}$ & $\begin{array}{c}.2(t=3.36) \\
.3(t=4.79) \\
R^{2}=.13\end{array}$ & $\begin{array}{c}.25(t=5.70) \\
.25(t=5.73) \\
R^{2}=.12\end{array}$ & Yes & - & No & (Yes) \\
\hline \multirow{2}{*}{$1 \mathrm{~b}}$. & $\begin{array}{c}-.7(t=18.95) \\
-.2(t=3.70) \\
R^{2}=.53\end{array}$ & $\begin{array}{c}-.2(t=4.01) \\
-.7(t=19.27) \\
R^{2}=.53\end{array}$ & $\begin{array}{c}-.45(t=-11.19) \\
-.45(t=-11.44) \\
R^{2}=.24\end{array}$ & Yes & - & No & Yes \\
\hline & $\begin{aligned}-.3(t & =5.03) \\
-.2(t & =3.14) \\
R^{2} & =.13\end{aligned}$ & $\begin{aligned}-.2(t & =3.25) \\
-.3(t & =5.09) \\
R^{2} & =.13\end{aligned}$ & $\begin{array}{c}-.25(t=-5.61) \\
-.25(t=-5.80) \\
R^{2}=.12\end{array}$ & Yes & - & No & (Yes) \\
\hline 2. & $\begin{array}{c}.7(t=19.43) \\
.2(t=3.99) \\
R^{2}=.53\end{array}$ & $\begin{array}{c}-.7(t=19.09) \\
-.2(t=3.78) \\
R^{2}=.53\end{array}$ & $\begin{array}{c}.00(t=.01) \\
.00(t=.00) \\
R^{2}=.00\end{array}$ & Yes & - & $\begin{array}{l}100 \% \\
100 \%\end{array}$ & Yes \\
\hline \multirow{2}{*}{3.} & $\begin{array}{c}.7(t=19.94) \\
.0(t=.01) \\
R^{2}=.49\end{array}$ & $\begin{array}{c}.0(t=.01) \\
.7(t=19.89) \\
R^{2}=.49\end{array}$ & $\begin{array}{c}.35(t=7.61) \\
.35(t=7.38) \\
R^{2}=.24\end{array}$ & Yes & $\begin{array}{l}100 \% \\
100 \%\end{array}$ & No & Yes \\
\hline & $\begin{array}{c}.2(t=3.38) \\
.0(t=.00) \\
R^{2}=.04\end{array}$ & $\begin{array}{c}.0(t=.01) \\
.2(t=3.17) \\
R^{2}=.04\end{array}$ & $\begin{array}{c}.10(t=1.88) \\
.10(t=1.90) \\
R^{2}=.02\end{array}$ & Yes & $\begin{array}{l}20 \% \\
40 \%\end{array}$ & $\begin{array}{l}80 \% \\
60 \%\end{array}$ & (Yes) \\
\hline 4. & $\begin{array}{c}.0(t=.00) \\
.0(t=.01) \\
R^{2}=.00\end{array}$ & $\begin{array}{c}.0(t=.01) \\
.0(t=.00) \\
R^{2}=.00\end{array}$ & $\begin{array}{c}.00(t=.00) \\
.00(t=.00) \\
R^{2}=.00\end{array}$ & - & No & - & - \\
\hline
\end{tabular}




\section{Appendix E}

\section{ANOVA Results-Model 1 (Reflective Measures)}

Tables E1 to E4 present the ANOVA results for model 1 (reflective measures) explaining MAB by method (PLS-POS/FIMIX-PLS) and the six design factors. All significant and substantial effects (i.e., all effects that explain more than 2 percent of the total variance in MAB implying a partial $\eta^{2}$ of more than .02) are highlighted in grey.

We find that the $R^{2}$, structural model heterogeneity, data distribution, and the interaction of structural model heterogeneity and $R^{2}$ have a substantial and significant effect on the MAB of both methods. Furthermore, there is a significant and substantial difference in the parameter recovery (MAB) of the two methods (PLS-POS and FIMIX-PLS) and for the interaction effects between the method and structural model heterogeneity and between the method and $R^{2}$.

\begin{tabular}{|c|c|c|c|c|}
\hline Source of Variance in MAB & df & $\mathbf{F}$ & Sig. & Partial $\eta^{2}$ \\
\hline Intercept & 1 & $14,658.62$ & .000 & .568 \\
\hline $\mathrm{SMH}$ & 3 & $1,121.71$ & .000 & .232 \\
\hline $\mathrm{R}^{2}$ & 3 & $1,948.85$ & .000 & .344 \\
\hline Sample Size & 2 & 70.77 & .000 & .013 \\
\hline Reliability & 1 & 1.88 & .170 & .000 \\
\hline Data Distribution & 1 & 497.52 & .000 & .043 \\
\hline RSS & 1 & 22.62 & .000 & .002 \\
\hline $\mathrm{SMH} \times R^{2}$ & 9 & 178.96 & .000 & .126 \\
\hline SMH $\times$ Sample Size & 6 & 9.64 & .000 & .005 \\
\hline SMH $\times$ Reliability & 3 & 1.33 & .262 & .000 \\
\hline SMH $\times$ Data Distribution & 3 & 21.15 & .000 & .006 \\
\hline $\mathrm{SMH} \times \mathrm{RSS}$ & 3 & 25.17 & .000 & .007 \\
\hline$R^{2} \times$ Sample Size & 6 & 11.44 & .000 & .006 \\
\hline$R^{2} \times$ Reliability & 3 & .75 & .524 & .000 \\
\hline$R^{2} \times$ Data Distribution & 3 & 14.72 & .000 & .004 \\
\hline$R^{2} \times \mathrm{RSS}$ & 3 & 29.76 & .000 & .008 \\
\hline Sample Size $\times$ Reliability & 2 & .48 & .620 & .000 \\
\hline Sample Size $\times$ Data Distribution & 2 & 14.17 & .000 & .003 \\
\hline Sample Size $\times$ RSS & 2 & 63.92 & .000 & .011 \\
\hline Reliability $\times$ Data Distribution & 1 & 4.04 & .044 & .000 \\
\hline Reliability $\times$ RSS & 1 & .11 & .735 & .000 \\
\hline Data Distribution $\times$ RSS & 1 & 267.72 & .000 & .023 \\
\hline SMH $\times R^{2} \times$ Sample Size & 18 & 1.75 & .026 & .003 \\
\hline SMH $\times R^{2} \times$ Reliability & 9 & 1.27 & .249 & .001 \\
\hline $\mathrm{SMH} \times R^{2} \times$ Data Distribution & 9 & 6.00 & .000 & .005 \\
\hline $\mathrm{SMH} \times R^{2} \times \mathrm{RSS}$ & 9 & 2.32 & .013 & .002 \\
\hline SMH $\times$ Sample Size $\times$ Reliability & 6 & 1.39 & .216 & .001 \\
\hline
\end{tabular}

Note: $d f=$ degrees of freedom; $M A B=$ mean absolute bias; $R S S=$ relative segment size; $S M H=$ structural model heterogeneity; all significant and substantial effects (i.e., all effects that explain more than $2 \%$ of the total variance in MAB implying a partial $\eta^{2}$ of more than .02) are highlighted in grey. 


\begin{tabular}{|c|c|c|c|c|}
\hline Source of Variance in MAB & df & $\mathbf{F}$ & Sig. & Partial $\eta^{2}$ \\
\hline SMH $\times$ Sample Size $\times$ Data Distribution & 6 & 5.22 & .000 & .003 \\
\hline SMH $\times$ Sample Size $\times$ RSS & 6 & 9.23 & .000 & .005 \\
\hline SMH $\times$ Reliability $\times$ Data Distribution & 3 & 2.19 & .087 & .001 \\
\hline SMH $\times$ Reliability $\times$ RSS & 3 & 3.50 & .015 & .001 \\
\hline $\mathrm{SMH} \times$ Data Distribution $\times \mathrm{RSS}$ & 3 & 2.30 & .075 & .001 \\
\hline$R^{2} \times$ Sample Size $\times$ Reliability & 6 & 1.88 & .080 & .001 \\
\hline$R^{2} \times$ Sample Size $\times$ Data Distribution & 6 & 1.83 & .089 & .001 \\
\hline$R^{2} \times$ Sample Size $\times$ RSS & 6 & 13.00 & .000 & .007 \\
\hline$R^{2} \times$ Reliability $\times$ Data Distribution & 3 & 1.85 & .135 & .000 \\
\hline$R^{2} \times$ Reliability $\times$ RSS & 3 & .42 & .740 & .000 \\
\hline$R^{2} \times$ Data Distribution $\times$ RSS & 3 & 7.83 & .000 & .002 \\
\hline Sample Size $\times$ Reliability $\times$ Data Distribution & 2 & 1.65 & .191 & .000 \\
\hline Sample Size $\times$ Reliability $\times$ RSS & 2 & 2.19 & .112 & .000 \\
\hline Sample Size $\times$ Data Distribution $\times$ RSS & 2 & 17.14 & .000 & .003 \\
\hline Reliability $\times$ Data Distribution $\times$ RSS & 1 & 1.08 & .299 & .000 \\
\hline SMH $\times R^{2} \times$ Sample Size $\times$ Reliability & 18 & .53 & .948 & .001 \\
\hline SMH $\times R^{2} \times$ Sample Size $\times$ Data Distribution & 18 & 1.68 & .036 & .003 \\
\hline SMH $\times R^{2} \times$ Sample Size $\times$ RSS & 18 & 2.11 & .004 & .003 \\
\hline SMH $\times R^{2} \times$ Reliability $\times$ Data Distribution & 9 & .68 & .725 & .001 \\
\hline $\mathrm{SMH} \times R^{2} \times$ Reliability $\times \mathrm{RSS}$ & 9 & .80 & .614 & .001 \\
\hline $\mathrm{SMH} \times R^{2} \times$ Data Distribution $\times \mathrm{RSS}$ & 9 & 1.52 & .135 & .001 \\
\hline SMH $\times$ Sample Size $\times$ Reliability $\times$ Data Distribution & 6 & .60 & .730 & .000 \\
\hline SMH $\times$ Sample Size $\times$ Reliability $\times$ RSS & 6 & .79 & .577 & .000 \\
\hline SMH $\times$ Sample Size $\times$ Data Distribution $\times$ RSS & 6 & 2.41 & .025 & .001 \\
\hline SMH $\times$ Reliability $\times$ Data Distribution $\times$ RSS & 3 & 2.06 & .104 & .001 \\
\hline$R^{2} \times$ Sample Size $\times$ Reliability $\times$ Data Distribution & 6 & 1.52 & .168 & .001 \\
\hline$R^{2} \times$ Sample Size $\times$ Reliability $\times$ RSS & 6 & 1.04 & .399 & .001 \\
\hline$R^{2} \times$ Sample Size $\times$ Data Distribution $\times$ RSS & 6 & 4.75 & .000 & .003 \\
\hline$R^{2} \times$ Reliability $\times$ Data Distribution $\times$ RSS & 3 & .26 & .851 & .000 \\
\hline Sample Size $\times$ Reliability $\times$ Data Distribution $\times$ RSS & 2 & .53 & .588 & .000 \\
\hline SMH $\times R^{2} \times$ Sample Size $\times$ Reliability $\times$ Data Distribution & 18 & .70 & .817 & .001 \\
\hline SMH $\times R^{2} \times$ Sample Size $\times$ Reliability $\times$ RSS & 18 & .70 & .811 & .001 \\
\hline $\mathrm{SMH} \times R^{2} \times$ Sample Size $\times$ Data Distribution $\times \mathrm{RSS}$ & 18 & .99 & .473 & .002 \\
\hline SMH $\times R^{2} \times$ Reliability $\times$ Data Distribution $\times$ RSS & 9 & .50 & .874 & .000 \\
\hline SMH $\times$ Sample Size $\times$ Reliability $\times$ Data Distribution $\times$ RSS & 6 & 1.71 & .115 & .001 \\
\hline$R^{2} \times$ Sample Size $\times$ Reliability $\times$ Data Distribution $\times$ RSS & 6 & 1.41 & .206 & .001 \\
\hline $\mathrm{SMH} \times R^{2} \times$ Sample Size $\times$ Reliability $\times$ Data Distribution $\times$ RSS & 18 & .96 & .502 & .002 \\
\hline Error & 11,136 & & & \\
\hline
\end{tabular}

Note: $d f=$ degrees of freedom; $M A B=$ mean absolute bias; $R S S=$ relative segment size; $S M H=$ structural model heterogeneity. 


\begin{tabular}{|c|c|c|c|c|}
\hline Source of Variance in MAB & df & $\mathbf{F}$ & Sig. & Partial $\eta^{2}$ \\
\hline Method & 1 & 952.31 & .000 & .079 \\
\hline Method $\times$ SMH & 3 & 217.47 & .000 & .055 \\
\hline Method $\times R^{2}$ & 3 & 137.14 & .000 & .036 \\
\hline Method $\times$ Sample Size & 2 & 4.66 & .009 & .001 \\
\hline Method $\times$ Reliability & 1 & .00 & .974 & .000 \\
\hline Method $\times$ Data Distribution & 1 & 87.97 & .000 & .008 \\
\hline Method $\times$ RSS & 1 & 104.01 & .000 & .009 \\
\hline Method $\times \mathrm{SMH} \times R^{2}$ & 9 & 12.84 & .000 & .010 \\
\hline Method $\times$ SMH $\times$ Sample Size & 6 & 2.79 & .010 & .002 \\
\hline Method $\times$ SMH $\times$ Reliability & 3 & .26 & .854 & .000 \\
\hline Method $\times$ SMH $\times$ Data Distribution & 3 & 37.26 & .000 & .010 \\
\hline Method $\times$ SMH $\times$ RSS & 3 & .88 & .450 & .000 \\
\hline Method $\times R^{2} \times$ Sample Size & 6 & 1.84 & .087 & .001 \\
\hline Method $\times R^{2} \times$ Reliability & 3 & .02 & .995 & .000 \\
\hline Method $\times R^{2} \times$ Data Distribution & 3 & 19.48 & .000 & .005 \\
\hline Method $\times R^{2} \times$ RSS & 3 & 3.98 & .008 & .001 \\
\hline Method $\times$ Sample Size $\times$ Reliability & 2 & .27 & .765 & .000 \\
\hline Method $\times$ Sample Size $\times$ Data Distribution & 2 & 17.60 & .000 & .003 \\
\hline Method $\times$ Sample Size $\times$ RSS & 2 & 16.60 & .000 & .003 \\
\hline Method $\times$ Reliability $\times$ Data Distribution & 1 & .02 & .876 & .000 \\
\hline Method $\times$ Reliability $\times$ RSS & 1 & .149 & .700 & .000 \\
\hline Method $\times$ Data Distribution $\times$ RSS & 1 & 14.37 & .000 & .001 \\
\hline Method $\times S M H \times R^{2} \times$ Sample Size & 18 & .89 & .589 & .001 \\
\hline Method $\times \mathrm{SMH} \times R^{2} \times$ Reliability & 9 & 1.33 & .215 & .001 \\
\hline Method $\times \mathrm{SMH} \times R^{2} \times$ Data Distribution & 9 & 2.07 & .029 & .002 \\
\hline Method $\times \mathrm{SMH} \times R^{2} \times \mathrm{RSS}$ & 9 & 4.56 & .000 & .004 \\
\hline Method $\times$ SMH $\times$ Sample Size $\times$ Reliability & 6 & .73 & .626 & .000 \\
\hline Method $\times$ SMH $\times$ Sample Size $\times$ Data Distribution & 6 & 3.94 & .001 & .002 \\
\hline Method $\times$ SMH $\times$ Sample Size $\times$ RSS & 6 & 1.72 & .112 & .001 \\
\hline Method $\times$ SMH $\times$ Reliability $\times$ Data Distribution & 3 & .74 & .527 & .000 \\
\hline Method $\times$ SMH $\times$ Reliability $\times$ RSS & 3 & 1.02 & .381 & .000 \\
\hline Method $\times$ SMH $\times$ Data Distribution $\times$ RSS & 3 & 18.88 & .000 & .005 \\
\hline Method $\times R^{2} \times$ Sample Size $\times$ Reliability & 6 & .28 & .945 & .000 \\
\hline Method $\times R^{2} \times$ Sample Size $\times$ Data Distribution & 6 & 2.09 & .051 & .001 \\
\hline Method $\times R^{2} \times$ Sample Size $\times$ RSS & 6 & 3.57 & .002 & .002 \\
\hline Method $\times R^{2} \times$ Reliability $\times$ Data Distribution & 3 & .29 & .835 & .000 \\
\hline Method $\times R^{2} \times$ Reliability $\times$ RSS & 3 & 1.28 & .278 & .000 \\
\hline Method $\times R^{2} \times$ Data Distribution $\times$ RSS & 3 & 8.97 & .000 & .002 \\
\hline Method $\times$ Sample Size $\times$ Reliability $\times$ Data Distribution & 2 & .69 & .501 & .000 \\
\hline Method $\times$ Sample Size $\times$ Reliability $\times$ RSS & 2 & .13 & .876 & .000 \\
\hline Method $\times$ Sample Size $\times$ Data Distribution $\times$ RSS & 2 & 8.98 & .000 & .002 \\
\hline Method $\times$ Reliability $\times$ Data Distribution $\times$ RSS & 1 & .00 & .993 & .000 \\
\hline
\end{tabular}

Note: $d f=$ degrees of freedom; $M A B=$ mean absolute bias; $R S S=$ relative segment size; $S M H=$ structural model heterogeneity; all significant and substantial effects (i.e., all effects that explain more than $2 \%$ of the total variance in MAB implying a partial $\eta^{2}$ of more than .02) are highlighted in grey. 


\begin{tabular}{|c|c|c|c|c|}
\hline Source of Variance in MAB & df & $\mathbf{F}$ & Sig. & Partial $\eta^{2}$ \\
\hline Method $\times \mathrm{SMH} \times R^{2} \times$ Sample Size $\times$ Reliability & 18 & .56 & .930 & .001 \\
\hline Method $\times \mathrm{SMH} \times R^{2} \times$ Sample Size $\times$ Data Distribution & 18 & 1.95 & .009 & .003 \\
\hline Method $\times \mathrm{SMH} \times R^{2} \times$ Sample Size $\times \mathrm{RSS}$ & 18 & 1.47 & .092 & .002 \\
\hline Method $\times \mathrm{SMH} \times R^{2} \times$ Reliability $\times$ Data Distribution & 9 & .95 & .484 & .001 \\
\hline Method $\times \mathrm{SMH} \times R^{2} \times$ Reliability $\times \mathrm{RSS}$ & 9 & 1.07 & .380 & .001 \\
\hline Method $\times \mathrm{SMH} \times R^{2} \times$ Data Distribution $\times \mathrm{RSS}$ & 9 & 1.96 & .040 & .002 \\
\hline Method $\times$ SMH $\times$ Sample Size $\times$ Reliability $\times$ Data Distribution & 6 & .54 & .775 & .000 \\
\hline Method $\times$ SMH $\times$ Sample Size $\times$ Reliability $\times$ RSS & 6 & 1.23 & .286 & .001 \\
\hline Method $\times$ SMH $\times$ Sample Size $\times$ Data Distribution $\times$ RSS & 6 & 2.62 & .015 & .001 \\
\hline Method $\times$ SMH $\times$ Reliability $\times$ Data Distribution $\times$ RSS & 3 & .30 & .828 & .000 \\
\hline Method $\times R^{2} \times$ Sample Size $\times$ Reliability $\times$ Data Distribution & 6 & 1.20 & .305 & .001 \\
\hline Method $\times R^{2} \times$ Sample Size $\times$ Reliability $\times$ RSS & 6 & .56 & .766 & .000 \\
\hline Method $\times R^{2} \times$ Sample Size $\times$ Data Distribution $\times$ RSS & 6 & 2.59 & .016 & .001 \\
\hline Method $\times R^{2} \times$ Reliability $\times$ Data Distribution $\times$ RSS & 3 & .34 & .798 & .000 \\
\hline Method $\times$ Sample Size $\times$ Reliability $\times$ Data Distribution $\times$ RSS & 2 & .34 & .711 & .000 \\
\hline Method $\times \mathrm{SMH} \times R^{2} \times$ Sample Size $\times$ Reliability $\times$ Data Distribution & 18 & .49 & .965 & .001 \\
\hline Method $\times \mathrm{SMH} \times R^{2} \times$ Sample Size $\times$ Reliability $\times$ RSS & 18 & .44 & .980 & .001 \\
\hline Method $\times \mathrm{SMH} \times R^{2} \times$ Sample Size $\times$ Data Distribution $\times \mathrm{RSS}$ & 18 & 1.76 & .024 & .003 \\
\hline Method $\times \mathrm{SMH} \times R^{2} \times$ Reliability $\times$ Data Distribution $\times$ RSS & 9 & .47 & .897 & .000 \\
\hline Method $\times$ SMH $\times$ Sample Size $\times$ Reliability $\times$ Data Distribution $\times$ RSS & 6 & 1.62 & .138 & .001 \\
\hline Method $\times R^{2} \times$ Sample Size $\times$ Reliability $\times$ Data Distribution $\times$ RSS & 6 & 32 & .928 & .000 \\
\hline Method $\times \mathrm{SMH} \times R^{2} \times$ Sample Size $\times$ Reliability $\times$ Data Distribution $\times$ RSS & 18 & .83 & .667 & .001 \\
\hline Error(Method) & 11,136 & & & \\
\hline
\end{tabular}

Note: $d f=$ degrees of freedom; $M A B=$ mean absolute bias; $R S S=$ relative segment size; $S M H=$ structural model heterogeneity. 


\section{Appendix F}

\section{ANOVA Results-Model 2 (Formative Measures)}

Tables F1 to F7 present the ANOVA results for model 2 (formative measures) explaining MAB by method (PLS-POS/FIMIX-PLS) and the seven design factors. All significant and substantial effects (i.e., all effects that explain more than 2 percent of the total variance in MAB implying a partial $\eta^{2}$ of more than .02) are highlighted in grey.

We find that the $R^{2}$, structural and measurement model heterogeneity, sample size, multicollinearity and data distribution, the interaction of structural and measurement model heterogeneity, and the interaction of sample size and relative segment size have a substantial and significant effect on the MAB of both methods. Furthermore, there is a significant and substantial difference in the parameter recovery (MAB) of the two methods (PLS-POS and FIMIX-PLS) and for the two-way interaction effects between method and $R^{2}$, multicollinearity, and structural and measurement model heterogeneity. Method even has a significant and substantial interaction effect with both structural and measurement model heterogeneity (three-way interaction).

\section{Table F1. Between-Subjects Effects (Part I)}

\begin{tabular}{|c|c|c|c|c|}
\hline Source of Variance in MAB & df & $\mathbf{F}$ & Sig. & Partial $\eta^{2}$ \\
\hline Intercept & 1 & $142,696.80$ & .00 & .740 \\
\hline $\mathrm{SMH}$ & 3 & $7,605.33$ & .00 & .313 \\
\hline $\mathrm{MMH}$ & 2 & $2,912.99$ & .00 & .104 \\
\hline$R^{2}$ & 3 & $4,286.31$ & .00 & .204 \\
\hline Sample Size & 2 & 864.77 & .00 & .033 \\
\hline RSS & 1 & 629.83 & .00 & .012 \\
\hline Data Distribution & 1 & $1,465.75$ & .00 & .028 \\
\hline Multicollinearity & 2 & 848.18 & .00 & .033 \\
\hline $\mathrm{SMH} \times \mathrm{MMH}$ & 6 & 298.09 & .00 & .034 \\
\hline $\mathrm{SMH} \times R^{2}$ & 9 & 44.28 & .00 & .008 \\
\hline $\mathrm{MMH} \times R^{2}$ & 6 & 5.82 & .00 & .006 \\
\hline
\end{tabular}

Note: $\quad d f=$ degrees of freedom; $M A B=$ mean absolute bias; $M M H=$ measurement model heterogeneity; RSS = relative segment size; $S M H$ = structural model heterogeneity; all significant and substantial effects (i.e., all effects that explain more than $2 \%$ of the total variance in MAB implying a partial $\eta^{2}$ of more than .02) are highlighted in grey. 


\begin{tabular}{|c|c|c|c|c|}
\hline Source of Variance in MAB & df & $\mathbf{F}$ & Sig. & Partial $\eta^{2}$ \\
\hline SMH $\times$ Sample Size & 6 & 31.10 & .00 & .004 \\
\hline MMH $\times$ Sample Size & 4 & 15.06 & .00 & .001 \\
\hline$R^{2} \times$ Sample Size & 6 & 46.43 & .00 & .006 \\
\hline $\mathrm{SMH} \times \mathrm{RSS}$ & 3 & 78.68 & .00 & .005 \\
\hline $\mathrm{MMH} \times \mathrm{RSS}$ & 2 & .69 & .50 & .000 \\
\hline$R^{2} \times \mathrm{RSS}$ & 3 & 87.86 & .00 & .005 \\
\hline Sample Size $\times$ RSS & 2 & $1,426.86$ & .00 & .054 \\
\hline $\mathrm{SMH} \times$ Data Distribution & 3 & 12.04 & .00 & .001 \\
\hline $\mathrm{MMH} \times$ Data Distribution & 2 & 7.61 & .00 & .000 \\
\hline$R^{2} \times$ Data Distribution & 3 & 3.21 & .02 & .000 \\
\hline Sample Size $\times$ Data Distribution & 2 & 28.39 & .00 & .001 \\
\hline RSS $\times$ Data Distribution & 1 & 2.26 & .13 & .000 \\
\hline $\mathrm{SMH} \times$ Multicollinearity & 6 & 109.17 & .00 & .013 \\
\hline $\mathrm{MMH} \times$ Multicollinearity & 4 & 287.84 & .00 & .022 \\
\hline$R^{2} \times$ Multicollinearity & 6 & 5.39 & .00 & .001 \\
\hline Sample Size $\times$ Multicollinearity & 4 & 28.36 & .00 & .002 \\
\hline RSS $\times$ Multicollinearity & 2 & 15.71 & .00 & .001 \\
\hline Data Distribution $\times$ Multicollinearity & 2 & 16.50 & .00 & .001 \\
\hline $\mathrm{SMH} \times \mathrm{MMH} \times R^{2}$ & 18 & 25.86 & .00 & .009 \\
\hline $\mathrm{SMH} \times \mathrm{MMH} \times$ Sample Size & 12 & 5.18 & .00 & .001 \\
\hline $\mathrm{SMH} \times R^{2} \times$ Sample Size & 18 & .78 & .73 & .000 \\
\hline $\mathrm{MMH} \times R^{2} \times$ Sample Size & 12 & .48 & .93 & .000 \\
\hline $\mathrm{SMH} \times \mathrm{MMH} \times \mathrm{RSS}$ & 6 & 5.48 & .00 & .001 \\
\hline $\mathrm{SMH} \times R^{2} \times \mathrm{RSS}$ & 9 & .60 & .80 & .000 \\
\hline $\mathrm{MMH} \times R^{2} \times \mathrm{RSS}$ & 6 & 2.66 & .01 & .000 \\
\hline SMH $\times$ Sample Size $\times$ RSS & 6 & 42.87 & .00 & .005 \\
\hline $\mathrm{MMH} \times$ Sample Size $\times$ RSS & 4 & 6.23 & .00 & .000 \\
\hline$R^{2} \times$ Sample Size $\times$ RSS & 6 & 59.73 & .00 & .007 \\
\hline $\mathrm{SMH} \times \mathrm{MMH} \times$ Data Distribution & 6 & 3.35 & .00 & .000 \\
\hline $\mathrm{SMH} \times R^{2} \times$ Data Distribution & 9 & 12.58 & .00 & .002 \\
\hline $\mathrm{MMH} \times R^{2} \times$ Data Distribution & 6 & 1.79 & .10 & .000 \\
\hline SMH $\times$ Sample Size $\times$ Data Distribution & 6 & 9.02 & .00 & .001 \\
\hline MMH $\times$ Sample Size $\times$ Data Distribution & 4 & 2.33 & .05 & .000 \\
\hline$R^{2} \times$ Sample Size $\times$ Data Distribution & 6 & 2.76 & .01 & .000 \\
\hline $\mathrm{SMH} \times \mathrm{RSS} \times$ Data Distribution & 3 & 13.81 & .00 & .001 \\
\hline $\mathrm{MMH} \times \mathrm{RSS} \times$ Data Distribution & 2 & 1.50 & .22 & .000 \\
\hline$R^{2} \times \mathrm{RSS} \times$ Data Distribution & 3 & 2.64 & .05 & .000 \\
\hline Sample Size $\times$ RSS $\times$ Data Distribution & 2 & 21.48 & .00 & .001 \\
\hline $\mathrm{SMH} \times \mathrm{MMH} \times$ Multicollinearity & 12 & 18.31 & .00 & .004 \\
\hline $\mathrm{SMH} \times R^{2} \times$ Multicollinearity & 18 & 7.30 & .00 & .003 \\
\hline $\mathrm{MMH} \times R^{2} \times$ Multicollinearity & 12 & 1.16 & .31 & .000 \\
\hline SMH $\times$ Sample Size $\times$ Multicollinearity & 12 & 11.15 & .00 & .003 \\
\hline $\mathrm{MMH} \times$ Sample Size $\times$ Multicollinearity & 8 & 3.17 & .00 & .001 \\
\hline$R^{2} \times$ Sample Size $\times$ Multicollinearity & 12 & .88 & .57 & .000 \\
\hline $\mathrm{SMH} \times \mathrm{RSS} \times$ Multicollinearity & 6 & 12.44 & .00 & .001 \\
\hline $\mathrm{MMH} \times \mathrm{RSS} \times$ Multicollinearity & 4 & 8.08 & .00 & .001 \\
\hline
\end{tabular}

Note: $d f=$ degrees of freedom; $M A B=$ mean absolute bias; $M M H=$ measurement model heterogeneity; RSS = relative segment size; $S M H=$ structural model heterogeneity; all significant and substantial effects (i.e., all effects that explain more than $2 \%$ of the total variance in MAB implying a partial $\eta^{2}$ of more than .02) are highlighted in grey. 


\begin{tabular}{|c|c|c|c|c|}
\hline Source of Variance in MAB & df & $\mathbf{F}$ & Sig. & Partial $\eta^{2}$ \\
\hline $\mathrm{R}^{2} \times \mathrm{RSS} \times$ Multicollinearity & 6 & 1.29 & .26 & .000 \\
\hline Sample Size $\times$ RSS $\times$ Multicollinearity & 4 & 18.22 & .00 & .001 \\
\hline SMH $\times$ Data Distribution $\times$ Multicollinearity & 6 & .94 & .46 & .000 \\
\hline $\mathrm{MMH} \times$ Data Distribution $\times$ Multicollinearity & 4 & 3.81 & .00 & .000 \\
\hline$R^{2} \times$ Data Distribution $\times$ Multicollinearity & 6 & .88 & .51 & .000 \\
\hline Sample Size $\times$ Data Distribution $\times$ Multicollinearity & 4 & 11.09 & .00 & .001 \\
\hline RSS $\times$ Data Distribution $\times$ Multicollinearity & 2 & 12.97 & .00 & .001 \\
\hline $\mathrm{SMH} \times \mathrm{MMH} \times R^{2} \times$ Sample Size & 36 & .75 & .86 & .001 \\
\hline $\mathrm{SMH} \times \mathrm{MMH} \times R^{2} \times \mathrm{RSS}$ & 18 & .86 & .63 & .000 \\
\hline $\mathrm{SMH} \times \mathrm{MMH} \times$ Sample Size $\times \mathrm{RSS}$ & 12 & 5.31 & .00 & .001 \\
\hline SMH $\times R^{2} \times$ Sample Size $\times$ RSS & 18 & 1.92 & .01 & .001 \\
\hline $\mathrm{MMH} \times R^{2} \times$ Sample Size $\times \mathrm{RSS}$ & 12 & .36 & .98 & .000 \\
\hline $\mathrm{SMH} \times \mathrm{MMH} \times R^{2} \times$ Data Distribution & 18 & 1.65 & .04 & .001 \\
\hline $\mathrm{SMH} \times \mathrm{MMH} \times$ Sample Size $\times$ Data Distribution & 12 & 3.87 & .00 & .001 \\
\hline SMH $\times R^{2} \times$ Sample Size $\times$ Data Distribution & 18 & 1.36 & .14 & .000 \\
\hline $\mathrm{MMH} \times R^{2} \times$ Sample Size $\times$ Data Distribution & 12 & .68 & .78 & .000 \\
\hline $\mathrm{SMH} \times \mathrm{MMH} \times \mathrm{RSS} \times$ Data Distribution & 6 & 1.80 & .09 & .000 \\
\hline $\mathrm{SMH} \times R^{2} \times \mathrm{RSS} \times$ Data Distribution & 9 & 1.57 & .12 & .000 \\
\hline $\mathrm{MMH} \times R^{2} \times \mathrm{RSS} \times$ Data Distribution & 6 & .54 & .78 & .000 \\
\hline SMH $\times$ Sample Size $\times$ RSS $\times$ Data Distribution & 6 & 8.98 & .00 & .001 \\
\hline $\mathrm{MMH} \times$ Sample Size $\times$ RSS $\times$ Data Distribution & 4 & 3.19 & .01 & .000 \\
\hline$R^{2} \times$ Sample Size $\times$ RSS $\times$ Data Distribution & 6 & 1.04 & .40 & .000 \\
\hline $\mathrm{SMH} \times \mathrm{MMH} \times R^{2} \times$ Multicollinearity & 36 & 2.16 & .00 & .002 \\
\hline SMH $\times$ MMH $\times$ Sample Size $\times$ Multicollinearity & 24 & .79 & .75 & .000 \\
\hline SMH $\times R^{2} \times$ Sample Size $\times$ Multicollinearity & 36 & 1.62 & .01 & .001 \\
\hline $\mathrm{MMH} \times R^{2} \times$ Sample Size $\times$ Multicollinearity & 24 & 1.04 & .41 & .000 \\
\hline $\mathrm{SMH} \times \mathrm{MMH} \times \mathrm{RSS} \times$ Multicollinearity & 12 & 2.41 & .00 & .001 \\
\hline $\mathrm{SMH} \times R^{2} \times \mathrm{RSS} \times$ Multicollinearity & 18 & 1.19 & .26 & .000 \\
\hline $\mathrm{MMH} \times R^{2} \times \mathrm{RSS} \times$ Multicollinearity & 12 & 1.38 & .17 & .000 \\
\hline $\mathrm{SMH} \times$ Sample Size $\times$ RSS $\times$ Multicollinearity & 12 & 9.08 & .00 & .002 \\
\hline $\mathrm{MMH} \times$ Sample Size $\times$ RSS $\times$ Multicollinearity & 8 & 1.95 & .05 & .000 \\
\hline$R^{2} \times$ Sample Size $\times$ RSS $\times$ Multicollinearity & 12 & 1.38 & .17 & .000 \\
\hline $\mathrm{SMH} \times \mathrm{MMH} \times$ Data Distribution $\times$ Multicollinearity & 12 & 6.34 & .00 & .002 \\
\hline
\end{tabular}

Note: $\quad d f=$ degrees of freedom; $M A B=$ mean absolute bias; $M M H=$ measurement model heterogeneity; RSS = relative segment size; $S M H=$ structural model heterogeneity. 


\begin{tabular}{|c|c|c|c|c|}
\hline Source of Variance in MAB & df & $\mathbf{F}$ & Sig. & Partial $\eta^{2}$ \\
\hline $\mathrm{SMH} \times R^{2} \times$ Data Distribution $\times$ Multicollinearity & 18 & 1.72 & .03 & .001 \\
\hline $\mathrm{MMH} \times R^{2} \times$ Data Distribution $\times$ Multicollinearity & 12 & 1.12 & .34 & .000 \\
\hline SMH $\times$ Sample Size $\times$ Data Distribution $\times$ Multicollinearity & 12 & 10.19 & .00 & .002 \\
\hline MMH $\times$ Sample Size $\times$ Data Distribution $\times$ Multicollinearity & 8 & .87 & .54 & .000 \\
\hline$R^{2} \times$ Sample Size $\times$ Data Distribution $\times$ Multicollinearity & 12 & 2.23 & .01 & .001 \\
\hline SMH $\times$ RSS $\times$ Data Distribution $\times$ Multicollinearity & 6 & 9.02 & .00 & .001 \\
\hline $\mathrm{MMH} \times \mathrm{RSS} \times$ Data Distribution $\times$ Multicollinearity & 4 & .49 & .74 & .000 \\
\hline$R^{2} \times \mathrm{RSS} \times$ Data Distribution $\times$ Multicollinearity & 6 & 1.10 & .36 & .000 \\
\hline Sample Size $\times$ RSS $\times$ Data Distribution $\times$ Multicollinearity & 4 & 24.61 & .00 & .002 \\
\hline $\mathrm{SMH} \times \mathrm{MMH} \times R^{2} \times$ Sample Size $\times \mathrm{RSS}$ & 36 & .75 & .86 & .001 \\
\hline $\mathrm{SMH} \times \mathrm{MMH} \times R^{2} \times$ Sample Size $\times$ Data Distribution & 36 & .74 & .88 & .001 \\
\hline $\mathrm{SMH} \times \mathrm{MMH} \times R^{2} \times \mathrm{RSS} \times$ Data Distribution & 18 & 1.20 & .25 & .000 \\
\hline $\mathrm{SMH} \times \mathrm{MMH} \times$ Sample Size $\times \mathrm{RSS} \times$ Data Distribution & 12 & 1.62 & .08 & .000 \\
\hline $\mathrm{SMH} \times R^{2} \times$ Sample Size $\times$ RSS $\times$ Data Distribution & 18 & .69 & .83 & .000 \\
\hline $\mathrm{MMH} \times R^{2} \times$ Sample Size $\times$ RSS $\times$ Data Distribution & 12 & 1.20 & .27 & .000 \\
\hline $\mathrm{SMH} \times \mathrm{MMH} \times R^{2} \times$ Sample Size $\times$ Multicollinearity & 72 & 1.13 & .21 & .002 \\
\hline $\mathrm{SMH} \times \mathrm{MMH} \times R^{2} \times \mathrm{RSS} \times$ Multicollinearity & 36 & 1.66 & .01 & .001 \\
\hline $\mathrm{SMH} \times \mathrm{MMH} \times$ Sample Size $\times$ RSS $\times$ Multicollinearity & 24 & 1.66 & .02 & .001 \\
\hline SMH $\times R^{2} \times$ Sample Size $\times$ RSS $\times$ Multicollinearity & 36 & .52 & .99 & .000 \\
\hline MMH $\times R^{2} \times$ Sample Size $\times$ RSS $\times$ Multicollinearity & 24 & .75 & .81 & .000 \\
\hline $\mathrm{SMH} \times \mathrm{MMH} \times R^{2} \times$ Data Distribution $\times$ Multicollinearity & 36 & .95 & .55 & .001 \\
\hline $\mathrm{SMH} \times \mathrm{MMH} \times$ Sample Size $\times$ Data Distribution $\times$ Multicollinearity & 24 & 1.52 & .05 & .001 \\
\hline SMH $\times R^{2} \times$ Sample Size $\times$ Data Distribution $\times$ Multicollinearity & 36 & 1.33 & .09 & .001 \\
\hline MMH $\times R^{2} \times$ Sample Size $\times$ Data Distribution $\times$ Multicollinearity & 24 & .90 & .60 & .000 \\
\hline $\mathrm{SMH} \times \mathrm{MMH} \times \mathrm{RSS} \times$ Data Distribution $\times$ Multicollinearity & 12 & 1.52 & .11 & .000 \\
\hline $\mathrm{SMH} \times R^{2} \times \mathrm{RSS} \times$ Data Distribution $\times$ Multicollinearity & 18 & 1.90 & .01 & .001 \\
\hline $\mathrm{MMH} \times R^{2} \times \mathrm{RSS} \times$ Data Distribution $\times$ Multicollinearity & 12 & 1.45 & .14 & .000 \\
\hline SMH $\times$ Sample Size $\times$ RSS $\times$ Data Distribution $\times$ Multicollinearity & 12 & 8.65 & .00 & .002 \\
\hline MMH $\times$ Sample Size $\times$ RSS $\times$ Data Distribution $\times$ Multicollinearity & 8 & 1.13 & .34 & .000 \\
\hline$R^{2} \times$ Sample Size $\times$ RSS $\times$ Data Distribution $\times$ Multicollinearity & 12 & .85 & .60 & .000 \\
\hline $\mathrm{SMH} \times \mathrm{MMH} \times R^{2} \times$ Sample Size $\times$ RSS $\times$ Data Distribution & 36 & .98 & .51 & .001 \\
\hline $\mathrm{SMH} \times \mathrm{MMH} \times R^{2} \times$ Sample Size $\times \mathrm{RSS} \times$ Multicollinearity & 72 & .84 & .84 & .001 \\
\hline $\mathrm{SMH} \times \mathrm{MMH} \times R^{2} \times$ Sample Size $\times$ Data Distribution $\times$ Multicollinearity & 72 & 1.07 & .33 & .002 \\
\hline $\mathrm{SMH} \times \mathrm{MMH} \times R^{2} \times \mathrm{RSS} \times$ Data Distribution $\times$ Multicollinearity & 36 & 1.24 & .15 & .001 \\
\hline $\begin{array}{l}\mathrm{SMH} \times \mathrm{MMH} \times \text { Sample Size } \times \mathrm{RSS} \times \text { Data Distribution } \times \\
\text { Multicollinearity }\end{array}$ & 24 & 1.12 & .32 & .001 \\
\hline $\mathrm{SMH} \times R^{2} \times$ Sample Size $\times$ RSS $\times$ Data Distribution $\times$ Multicollinearity & 36 & 1.09 & .32 & .001 \\
\hline $\mathrm{MMH} \times R^{2} \times$ Sample Size $\times$ RSS $\times$ Data Distribution $\times$ Multicollinearity & 24 & .87 & .65 & .000 \\
\hline $\begin{array}{l}\mathrm{SMH} \times \mathrm{MMH} \times R^{2} \times \text { Sample Size } \times \mathrm{RSS} \times \text { Data Distribution } \times \\
\text { Multicollinearity }\end{array}$ & 72 & 1.05 & .36 & .002 \\
\hline Error & 50,112 & & & \\
\hline
\end{tabular}

Note: $\quad d f=$ degrees of freedom; $M A B=$ mean absolute bias; $M M H=$ measurement model heterogeneity; RSS = relative segment size; $S M H=$ structural model heterogeneity. 


\begin{tabular}{|c|c|c|c|c|}
\hline Source of Variance in MAB & df & $F$ & Sig. & Partial $\eta^{2}$ \\
\hline Method & 1 & $3,938.52$ & .00 & .073 \\
\hline Method $\times$ SMH & 3 & $3,987.98$ & .00 & .193 \\
\hline Method $\times$ MMH & 2 & $6,771.05$ & .00 & .213 \\
\hline Method $\times R^{2}$ & 3 & 826.32 & .00 & .047 \\
\hline Method $\times$ Sample Size & 2 & 227.55 & .00 & .009 \\
\hline Method $\times$ RSS & 1 & 171.66 & .00 & .003 \\
\hline Method $\times$ Data Distribution & 1 & 2.97 & .08 & .000 \\
\hline Method $\times$ Multicollinearity & 2 & $1,739.12$ & .00 & .065 \\
\hline Method $\times \mathrm{SMH} \times \mathrm{MMH}$ & 6 & 976.49 & .00 & .105 \\
\hline Method $\times \mathrm{SMH} \times R^{2}$ & 9 & 83.50 & .00 & .015 \\
\hline Method $\times \mathrm{MMH} \times R^{2}$ & 6 & 6.13 & .00 & .001 \\
\hline Method $\times$ SMH $\times$ Sample Size & 6 & 22.80 & .00 & .003 \\
\hline Method $\times$ MMH $\times$ Sample Size & 4 & 3.13 & .01 & .000 \\
\hline Method $\times R^{2} \times$ Sample Size & 6 & 3.95 & .00 & .000 \\
\hline Method $\times$ SMH $\times$ RSS & 3 & 60.96 & .00 & .004 \\
\hline Method $\times$ MMH $\times$ RSS & 2 & 12.78 & .00 & .001 \\
\hline Method $\times R^{2} \times \mathrm{RSS}$ & 3 & 15.69 & .00 & .001 \\
\hline Method $\times$ Sample Size $\times$ RSS & 2 & 163.40 & .00 & .006 \\
\hline Method $\times$ SMH $\times$ Data Distribution & 3 & 54.31 & .00 & .003 \\
\hline Method $\times$ MMH $\times$ Data Distribution & 2 & 3.39 & .03 & .000 \\
\hline Method $\times R^{2} \times$ Data Distribution & 3 & 5.19 & .00 & .000 \\
\hline Method $\times$ Sample Size $\times$ Data Distribution & 2 & 12.45 & .00 & .000 \\
\hline Method $\times$ RSS $\times$ Data Distribution & 1 & 56.16 & .00 & .001 \\
\hline Method $\times$ SMH $\times$ Multicollinearity & 6 & 372.96 & .00 & .043 \\
\hline Method $\times$ MMH $\times$ Multicollinearity & 4 & 257.24 & .00 & .020 \\
\hline Method $\times R^{2} \times$ Multicollinearity & 6 & 9.69 & .00 & .001 \\
\hline Method $\times$ Sample Size $\times$ Multicollinearity & 4 & 22.84 & .00 & .002 \\
\hline Method $\times$ RSS $\times$ Multicollinearity & 2 & 5.85 & .00 & .000 \\
\hline Method $\times$ Data Distribution $\times$ Multicollinearity & 2 & 11.81 & .00 & .000 \\
\hline Method $\times \mathrm{SMH} \times \mathrm{MMH} \times R^{2}$ & 18 & 11.49 & .00 & .004 \\
\hline Method $\times$ SMH $\times$ MMH $\times$ Sample Size & 12 & 2.44 & .00 & .001 \\
\hline Method $\times$ SMH $\times R^{2} \times$ Sample Size & 18 & 3.68 & .00 & .001 \\
\hline Method $\times \mathrm{MMH} \times R^{2} \times$ Sample Size & 12 & 1.39 & .16 & .000 \\
\hline Method $\times$ SMH $\times$ MMH $\times$ RSS & 6 & 14.80 & .00 & .002 \\
\hline Method $\times \mathrm{SMH} \times R^{2} \times \mathrm{RSS}$ & 9 & 12.50 & .00 & .002 \\
\hline Method $\times \mathrm{MMH} \times R^{2} \times \mathrm{RSS}$ & 6 & 2.61 & .02 & .000 \\
\hline Method $\times$ SMH $\times$ Sample Size $\times$ RSS & 6 & 47.94 & .00 & .006 \\
\hline Method $\times$ MMH $\times$ Sample Size $\times$ RSS & 4 & 13.37 & .00 & .001 \\
\hline Method $\times R^{2} \times$ Sample Size $\times$ RSS & 6 & 19.62 & .00 & .002 \\
\hline Method $\times$ SMH $\times$ MMH $\times$ Data Distribution & 6 & 1.74 & .11 & .000 \\
\hline Method $\times \mathrm{SMH} \times R^{2} \times$ Data Distribution & 9 & 5.01 & .00 & .001 \\
\hline Method $\times$ MMH $\times R^{2} \times$ Data Distribution & 6 & 3.04 & .01 & .000 \\
\hline Method $\times$ SMH $\times$ Sample Size $\times$ Data Distribution & 6 & 7.68 & .00 & .001 \\
\hline Method $\times$ MMH $\times$ Sample Size $\times$ Data Distribution & 4 & .30 & .88 & .000 \\
\hline Method $\times R^{2} \times$ Sample Size $\times$ Data Distribution & 6 & 3.34 & .00 & .000 \\
\hline Method $\times$ SMH $\times$ RSS $\times$ Data Distribution & 3 & 3.68 & .01 & .000 \\
\hline Method $\times$ MMH $\times$ RSS $\times$ Data Distribution & 2 & .76 & .47 & .000 \\
\hline Method $\times R^{2} \times$ RSS $\times$ Data Distribution & 3 & .43 & .73 & .000 \\
\hline Method $\times$ Sample Size $\times$ RSS $\times$ Data Distribution & 2 & 19.04 & .00 & .001 \\
\hline Method $\times \mathrm{SMH} \times \mathrm{MMH} \times$ Multicollinearity & 12 & 28.62 & .00 & .007 \\
\hline Method $\times$ SMH $\times R^{2} \times$ Multicollinearity & 18 & 5.04 & .00 & .002 \\
\hline Method $\times \mathrm{MMH} \times R^{2} \times$ Multicollinearity & 12 & .46 & .94 & .000 \\
\hline
\end{tabular}

Note: $d f=$ degrees of freedom; $M A B=$ mean absolute bias; $M M H=$ measurement model heterogeneity; RSS = relative segment size; $\mathrm{SMH}=$ structural model heterogeneity; all significant and substantial effects (i.e., all effects that explain more than $2 \%$ of the total variance in MAB implying a partial $\eta^{2}$ of more than .02) are highlighted in grey. 


\begin{tabular}{|c|c|c|c|c|}
\hline Source of Variance in MAB & df & $\mathbf{F}$ & Sig. & Partial $\eta^{2}$ \\
\hline Method $\times$ SMH $\times$ Sample Size $\times$ Multicollinearity & 12 & 11.91 & .00 & .003 \\
\hline Method $\times$ MMH $\times$ Sample Size $\times$ Multicollinearity & 8 & 1.40 & .19 & .000 \\
\hline Method $\times R^{2} \times$ Sample Size $\times$ Multicollinearity & 12 & .91 & .53 & .000 \\
\hline Method $\times$ SMH $\times$ RSS $\times$ Multicollinearity & 6 & 16.91 & .00 & .002 \\
\hline Method $\times$ MMH $\times$ RSS $\times$ Multicollinearity & 4 & 3.91 & .00 & .000 \\
\hline Method $\times R^{2} \times$ RSS $\times$ Multicollinearity & 6 & 1.19 & .31 & .000 \\
\hline Method $\times$ Sample Size $\times$ RSS $\times$ Multicollinearity & 4 & 20.68 & .00 & .002 \\
\hline Method $\times$ SMH $\times$ Data Distribution $\times$ Multicollinearity & 6 & 6.57 & .00 & .001 \\
\hline Method $\times$ MMH $\times$ Data Distribution $\times$ Multicollinearity & 4 & 3.63 & .01 & .000 \\
\hline Method $\times R^{2} \times$ Data Distribution $\times$ Multicollinearity & 6 & .99 & .43 & .000 \\
\hline Method $\times$ Sample Size $\times$ Data Distribution $\times$ Multicollinearity & 4 & 24.39 & .00 & .002 \\
\hline Method $\times$ RSS $\times$ Data Distribution $\times$ Multicollinearity & 2 & 28.84 & .00 & .001 \\
\hline Method $\times \mathrm{SMH} \times \mathrm{MMH} \times R^{2} \times$ Sample Size & 36 & 1.35 & .08 & .001 \\
\hline Method $\times \mathrm{SMH} \times \mathrm{MMH} \times R^{2} \times \mathrm{RSS}$ & 18 & 1.48 & .08 & .001 \\
\hline Method $\times$ SMH $\times \mathrm{MMH} \times$ Sample Size $\times \mathrm{RSS}$ & 12 & 1.99 & .02 & .000 \\
\hline Method $\times$ SMH $\times R^{2} \times$ Sample Size $\times$ RSS & 18 & 2.48 & .00 & .001 \\
\hline Method $\times$ MMH $\times R^{2} \times$ Sample Size $\times$ RSS & 12 & 2.34 & .01 & .001 \\
\hline Method $\times \mathrm{SMH} \times \mathrm{MMH} \times R^{2} \times$ Data Distribution & 18 & .86 & .63 & .000 \\
\hline Method $\times$ SMH $\times$ MMH $\times$ Sample Size $\times$ Data Distribution & 12 & 2.68 & .00 & .001 \\
\hline Method $\times \mathrm{SMH} \times R^{2} \times$ Sample Size $\times$ Data Distribution & 18 & 1.28 & .19 & .000 \\
\hline Method $\times \mathrm{MMH} \times R^{2} \times$ Sample Size $\times$ Data Distribution & 12 & .37 & .97 & .000 \\
\hline Method $\times \mathrm{SMH} \times \mathrm{MMH} \times \mathrm{RSS} \times$ Data Distribution & 6 & 1.18 & .32 & .000 \\
\hline Method $\times \mathrm{SMH} \times R^{2} \times \mathrm{RSS} \times$ Data Distribution & 9 & 3.45 & .00 & .001 \\
\hline Method $\times \mathrm{MMH} \times R^{2} \times \mathrm{RSS} \times$ Data Distribution & 6 & .51 & .80 & .000 \\
\hline Method $\times$ SMH $\times$ Sample Size $\times$ RSS $\times$ Data Distribution & 6 & 8.37 & .00 & .001 \\
\hline Method $\times$ MMH $\times$ Sample Size $\times$ RSS $\times$ Data Distribution & 4 & 1.21 & .31 & .000 \\
\hline Method $\times R^{2} \times$ Sample Size $\times$ RSS $\times$ Data Distribution & 6 & 1.13 & .34 & .000 \\
\hline Method $\times \mathrm{SMH} \times \mathrm{MMH} \times R^{2} \times$ Multicollinearity & 36 & 1.29 & .11 & .001 \\
\hline Method $\times$ SMH $\times$ MMH $\times$ Sample Size $\times$ Multicollinearity & 24 & 1.28 & .16 & .001 \\
\hline Method $\times$ SMH $\times R^{2} \times$ Sample Size $\times$ Multicollinearity & 36 & 1.36 & .08 & .001 \\
\hline Method $\times$ MMH $\times R^{2} \times$ Sample Size $\times$ Multicollinearity & 24 & 1.05 & .40 & .001 \\
\hline Method $\times \mathrm{SMH} \times \mathrm{MMH} \times \mathrm{RSS} \times$ Multicollinearity & 12 & 3.27 & .00 & .001 \\
\hline Method $\times \mathrm{SMH} \times R^{2} \times \mathrm{RSS} \times$ Multicollinearity & 18 & 1.02 & .43 & .000 \\
\hline Method $\times$ MMH $\times R^{2} \times$ RSS $\times$ Multicollinearity & 12 & 1.40 & .16 & .000 \\
\hline Method $\times$ SMH $\times$ Sample Size $\times$ RSS $\times$ Multicollinearity & 12 & 8.14 & .00 & .002 \\
\hline Method $\times$ MMH $\times$ Sample Size $\times$ RSS $\times$ Multicollinearity & 8 & 2.47 & .01 & .000 \\
\hline Method $\times R^{2} \times$ Sample Size $\times$ RSS $\times$ Multicollinearity & 12 & 1.36 & .18 & .000 \\
\hline Method $\times \mathrm{SMH} \times \mathrm{MMH} \times$ Data Distribution $\times$ Multicollinearity & 12 & 2.63 & .00 & .001 \\
\hline Method $\times \mathrm{SMH} \times R^{2} \times$ Data Distribution $\times$ Multicollinearity & 18 & 1.65 & .04 & .001 \\
\hline Method $\times \mathrm{MMH} \times R^{2} \times$ Data Distribution $\times$ Multicollinearity & 12 & .82 & .63 & .000 \\
\hline Method $\times$ SMH $\times$ Sample Size $\times$ Data Distribution $\times$ Multicollinearity & 12 & 7.24 & .00 & .002 \\
\hline Method $\times$ MMH $\times$ Sample Size $\times$ Data Distribution $\times$ Multicollinearity & 8 & 1.01 & .42 & .000 \\
\hline Method $\times R^{2} \times$ Sample Size $\times$ Data Distribution $\times$ Multicollinearity & 12 & 1.42 & .15 & .000 \\
\hline Method $\times$ SMH $\times$ RSS $\times$ Data Distribution $\times$ Multicollinearity & 6 & 6.94 & .00 & .001 \\
\hline Method $\times$ MMH $\times$ RSS $\times$ Data Distribution $\times$ Multicollinearity & 4 & 1.40 & .23 & .000 \\
\hline Method $\times R^{2} \times$ RSS $\times$ Data Distribution $\times$ Multicollinearity & 6 & 1.59 & .15 & .000 \\
\hline Method $\times$ Sample Size $\times$ RSS $\times$ Data Distribution $\times$ Multicollinearity & 4 & 15.65 & .00 & .001 \\
\hline Method $\times \mathrm{SMH} \times \mathrm{MMH} \times R^{2} \times$ Sample Size $\times \mathrm{RSS}$ & 36 & 1.88 & .00 & .001 \\
\hline Method $\times \mathrm{SMH} \times \mathrm{MMH} \times R^{2} \times$ Sample Size $\times$ Data Distribution & 36 & .80 & .80 & .001 \\
\hline Method $\times \mathrm{SMH} \times \mathrm{MMH} \times R^{2} \times \mathrm{RSS} \times$ Data Distribution & 18 & 1.00 & .45 & .000 \\
\hline
\end{tabular}

Note: $d f=$ degrees of freedom; $M A B=$ mean absolute bias; $M M H=$ measurement model heterogeneity; RSS = relative segment size; $S M H=$ structural model heterogeneity. 


\begin{tabular}{|c|c|c|c|c|}
\hline Source of Variance in MAB & df & $\mathbf{F}$ & Sig. & $\begin{array}{c}\text { Partial } \\
\eta^{2}\end{array}$ \\
\hline Method $\times \mathrm{SMH} \times \mathrm{MMH} \times$ Sample Size $\times \mathrm{RSS} \times$ Data Distribution & 12 & 2.14 & .01 & .001 \\
\hline Method $\times \mathrm{SMH} \times R^{2} \times$ Sample Size $\times \mathrm{RSS} \times$ Data Distribution & 18 & 1.53 & .07 & .001 \\
\hline Method $\times \mathrm{MMH} \times R^{2} \times$ Sample Size $\times \mathrm{RSS} \times$ Data Distribution & 12 & .77 & .68 & .000 \\
\hline Method $\times \mathrm{SMH} \times \mathrm{MMH} \times R^{2} \times$ Sample Size $\times$ Multicollinearity & 72 & .91 & .70 & .001 \\
\hline Method $\times \mathrm{SMH} \times \mathrm{MMH} \times R^{2} \times \mathrm{RSS} \times$ Multicollinearity & 36 & 1.28 & .12 & .001 \\
\hline Method $\times \mathrm{SMH} \times \mathrm{MMH} \times$ Sample Size $\times \mathrm{RSS} \times$ Multicollinearity & 24 & 1.95 & .00 & .001 \\
\hline Method $\times \mathrm{SMH} \times R^{2} \times$ Sample Size $\times \mathrm{RSS} \times$ Multicollinearity & 36 & 1.37 & .07 & .001 \\
\hline Method $\times \mathrm{MMH} \times R^{2} \times$ Sample Size $\times$ RSS $\times$ Multicollinearity & 24 & .90 & .60 & .000 \\
\hline Method $\times \mathrm{SMH} \times \mathrm{MMH} \times R^{2} \times$ Data Distribution $\times$ Multicollinearity & 36 & .98 & .50 & .001 \\
\hline Method $\times \mathrm{SMH} \times \mathrm{MMH} \times$ Sample Size $\times$ Data Distribution $\times$ Multicollinearity & 24 & 2.46 & .00 & .001 \\
\hline Method $\times \mathrm{SMH} \times R^{2} \times$ Sample Size $\times$ Data Distribution $\times$ Multicollinearity & 36 & 1.49 & .03 & .001 \\
\hline Method $\times \mathrm{MMH} \times R^{2} \times$ Sample Size $\times$ Data Distribution $\times$ Multicollinearity & 24 & .70 & .85 & .000 \\
\hline Method $\times \mathrm{SMH} \times \mathrm{MMH} \times \mathrm{RSS} \times$ Data Distribution $\times$ Multicollinearity & 12 & 1.75 & .05 & .000 \\
\hline Method $\times \mathrm{SMH} \times R^{2} \times \mathrm{RSS} \times$ Data Distribution $\times$ Multicollinearity & 18 & 1.71 & .03 & .001 \\
\hline Method $\times \mathrm{MMH} \times R^{2} \times \mathrm{RSS} \times$ Data Distribution $\times$ Multicollinearity & 12 & 1.37 & .17 & .000 \\
\hline Method $\times$ SMH $\times$ Sample Size $\times$ RSS $\times$ Data Distribution $\times$ Multicollinearity & 12 & 8.67 & .00 & .002 \\
\hline Method $\times$ MMH $\times$ Sample Size $\times$ RSS $\times$ Data Distribution $\times$ Multicollinearity & 8 & 1.29 & .24 & .000 \\
\hline Method $\times R^{2} \times$ Sample Size $\times$ RSS $\times$ Data Distribution $\times$ Multicollinearity & 12 & .78 & .68 & .000 \\
\hline Method $\times \mathrm{SMH} \times \mathrm{MMH} \times R^{2} \times$ Sample Size $\times \mathrm{RSS} \times$ Data Distribution & 36 & .85 & .73 & .001 \\
\hline Method $\times \mathrm{SMH} \times \mathrm{MMH} \times R^{2} \times$ Sample Size $\times$ RSS $\times$ Multicollinearity & 72 & 1.05 & .36 & .002 \\
\hline Method $\times \mathrm{SMH} \times \mathrm{MMH} \times R^{2} \times$ Sample Size $\times$ Data Distribution $\times$ Multicollinearity & 72 & 1.20 & .11 & .002 \\
\hline Method $\times \mathrm{SMH} \times \mathrm{MMH} \times R^{2} \times \mathrm{RSS} \times$ Data Distribution $\times$ Multicollinearity & 36 & 1.53 & .02 & .001 \\
\hline Method $\times$ SMH $\times$ MMH $\times$ Sample Size $\times$ RSS $\times$ Data Distribution $\times$ Multicollinearity & 24 & 2.53 & .00 & .001 \\
\hline Method $\times \mathrm{SMH} \times R^{2} \times$ Sample Size $\times$ RSS $\times$ Data Distribution $\times$ Multicollinearity & 36 & 1.33 & .09 & .001 \\
\hline Method $\times \mathrm{MMH} \times R^{2} \times$ Sample Size $\times$ RSS $\times$ Data Distribution $\times$ Multicollinearity & 24 & 1.25 & .18 & .001 \\
\hline $\begin{array}{l}\text { Method } \times \mathrm{SMH} \times \mathrm{MMH} \times R^{2} \times \text { Sample Size } \times \mathrm{RSS} \times \text { Data Distribution } \times \\
\text { Multicollinearity }\end{array}$ & 72 & .96 & .58 & .001 \\
\hline Error(Method) & 50,112 & & & \\
\hline
\end{tabular}

Note: $\quad d f=$ degrees of freedom; $M A B=$ mean absolute bias; $M M H=$ measurement model heterogeneity; RSS = relative segment size; $S M H=$ structural model heterogeneity.

\section{References}

Alavi, M., and Joachimsthaler, E. A. 1992. "Revisiting DSS Implementation Research: A Meta- Analysis of the Literature and Suggestions for Researchers," MIS Quarterly (16:1), pp. 95-116.

Anderberg, M. R. 1973. Cluster Analysis for Applications, New York: Academic Press.

Dennis, A. R., Wixom, B. H., and Vandenberg, R. J. 2001. "Understanding Fit and Appropriation Effects in Group Support Systems via Meta-Analysis," MIS Quarterly (25:2), pp. 167-193.

Diamantopoulos, A., and Winklhofer, H. M. 2001. "Index Construction with Formative Indicators: An Alternative to Scale Development," Journal of Marketing Research (38:2), pp. 269-277.

Esposito Vinzi, V., Trinchera, L., and Amato, S. 2010. "PLS Path Modeling: From Foundations to Recent Developments and Open Issues for Model Assessment and Improvement," in Handbook of Partial Least Squares: Concepts, Methods and Applications, V. Esposito Vinzi, W. W. Chin, J. Henseler, and H. Wang (eds.), Berlin: Springer, pp. 47-82.

Esposito Vinzi, V., Trinchera, L., Squillacciotti, S., and Tenenhaus, M. 2008. "REBUS-PLS: A Response-Based Procedure for Detecting Unit Segments in PLS Path Modelling," Applied Stochastic Models in Business \& Industry (24:5), pp. 439-458. 
Grewal, R., Cote, J. A., and Baumgartner, H. 2004. "Multicollinearity and Measurement Error in Structural Equation Models: Implications for Theory Testing," Marketing Science (23:4), pp. 519-529.

Gudergan, S. P., Ringle, C. M., Wende, S., and Will, A. 2008. “Confirmatory Tetrad Analysis in PLS Path Modeling,” Journal of Business Research (61:12), pp. 1238-1249.

Hahn, C., Johnson, M. D., Herrmann, A., and Huber, F. 2002. "Capturing Customer Heterogeneity Using a Finite Mixture PLS Approach,” Schmalenbach Business Review (SBR) (54:3), pp. 243-269.

Henseler, J., Ringle, C. M., and Sinkovics, R. R. 2009. "The Use of Partial Least Squares Path Modeling in International Marketing," in Advances in International Marketing, R. R. Sinkovics and P. N. Ghauri (eds.), Bingley, United Kingdom: Emerald Group Publishing Limited, pp. 277-320.

Henseler, J., and Sarstedt, M. 2012. “Goodness-of-Fit Indices for Partial Least Squares Path Modeling,” Computational Statistics, (http://link.springer.com/article/10.1007\%2Fs00180-012-0317-1).

Jarvis, C. B., MacKenzie, S. B., and Podsakoff, P. M. 2003. "A Critical Review of Construct Indicators and Measurement Model Misspecification in Marketing and Consumer Research," Journal of Consumer Research (30:2), pp. 199-218

Joseph, D., Kok-Yee, N., Koh, C., and Soon, A. 2007. "Turnover of Information Technology Professionals: A Narrative Review, Meta-Analytic Structural Equation Modeling, and Model Development," MIS Quarterly (31:3), pp. 547-577.

King, W. R., and He, J. 2006. "A Meta-Analysis of the Technology Acceptance Model,” Information \& Management (43:6), pp. 740-755.

Kohli, R., and Devaraj, S. 2003. "Measuring Information Technology Payoff: A Meta-Analysis of Structural Variables in Firm-Level Empirical Research," Information Systems Research (14:2), pp. 127-145.

Lee, G., and Xia, W. 2006. "Organizational Size and IT Innovation Adoption: A Meta-Analysis," Information \& Management (43:8), pp. 975-985.

Lohmöller, J.-B. 1989. Latent Variable Path Modeling with Partial Least Squares, Heidelberg: Physica.

Mason, C. H., and Perreault, W. D. 1991. “Collinearity, Power, and Interpretation of Multiple Regression Analysis," Journal of Marketing Research (28:3), pp. 268-280.

R Core Team. 2013. "R: A Language and Environment for Statistical Computing," R Foundation for Statistical Computing, Vienna.

Sabherwal, R., Jeyaraj, A., and Chowa, C. 2006. "Information System Success: Individual and Organizational Determinants," Management Science (52:12), pp. 1849-1864.

Sánchez, G., and Trinchera, L. 2013. "R Package PLSPM (version 0.3.5),” http://cran.r-project.org/web/packages/plspm/.

Sarstedt, M. 2008. “A Review of Recent Approaches for Capturing Heterogeneity in Partial Least Squares Path Modelling," Journal of Modelling in Management (3:2), pp. 140-161.

Schepers, J., and Wetzels, M. 2007. "A Meta-Analysis of the Technology Acceptance Model: Investigating Subjective Norm and Moderation Effects," Information \& Management (44:1), pp. 90-103.

Sharma, R., and Yetton, P. 2003. "The Contingent Effects of Management Support and Task Interdependence on Successful Information Systems Implementation," MIS Quarterly (27:4), pp. 533-555.

Sharma, R., and Yetton, P. 2007. "The Contingent Effects of Training, Technical Complexity, and Task Interdependence on Successful Information Systems Implementation," MIS Quarterly (31:2), pp. 219-238.

Squillacciotti, S. 2005. "Prediction Oriented Classification in PLS Path Modeling," in PLS \& Marketing: Proceedings of the $4^{\text {th }}$ International Symposium on PLS and Related Methods, T. Aluja, J. Casanovas, V. Esposito Vinzi and M. Tenenhaus (eds.), Paris: DECISIA, pp. 499-506.

Squillacciotti, S. 2010. "Prediction-Oriented Classification in PLS Path Modeling," in Handbook of Partial Least Squares: Concepts, Methods and Applications, V. Esposito Vinzi, W. W. Chin, J. Henseler, and H. Wang (eds.), Berlin: Springer, pp. 219-233.

Tenenhaus, M., Esposito Vinzi, V., Chatelin, Y.-M., and Lauro, C. 2005. "PLS Path Modeling," Computational Statistics \& Data Analysis (48:1), pp. 159-205

Wang, J., and Keil, M. 2007. “A Meta-Analysis Comparing the Sunk Cost Effect for IT and Non-IT Projects," Information Resources Management Journal (20:3), pp. 1-18.

Wedel, M., and Kamakura, W. 2000. Market Segmentation: Conceptual and Methodological Foundations (2 ${ }^{\text {nd }}$ ed.), New York: Kluwer Academic Publishers.

Wold, H. 1982. "Soft Modeling: The Basic Design and Some Extensions,” in: Systems Under Indirect Observations: Part I, K. G. Jöreskog and H. Wold (eds.), Amsterdam: North-Holland, pp. 1-54.

Wu, J., and Lederer, A. 2009. "A Meta-Analysis of the Role of Environment-Based Voluntariness in Information Technology Acceptance," MIS Quarterly (33:2), pp. 419-432. 